Florida International University

FIU Digital Commons

FIU Electronic Theses and Dissertations

University Graduate School

$11-17-2010$

\title{
A Comparison of Job Responsibility and Activities between Registered Dietitians with a Bachelor's Degree and Those with a Master's Degree
}

Stephanie M. Pillow

Florida International University, spillo01@fiu.edu

DOI: $10.25148 /$ etd.FI10120601

Follow this and additional works at: https:// digitalcommons.fiu.edu/etd

Part of the Dietetics and Clinical Nutrition Commons, $\underline{\text { Human and Clinical Nutrition }}$ Commons, and the Other Nutrition Commons

\section{Recommended Citation}

Pillow, Stephanie M., "A Comparison of Job Responsibility and Activities between Registered Dietitians with a Bachelor's Degree and Those with a Master's Degree" (2010). FIU Electronic Theses and Dissertations. 295.

https://digitalcommons.fiu.edu/etd/295 


\section{FLORIDA INTERNATIONAL UNIVERSITY}

Miami, Florida

A COMPARISON OF JOB RESPONSIBILITY AND ACTIVITIES BETWEEN REGISTERED DIETITIANS WITH A BACHELOR'S DEGREE AND THOSE WITH

A MASTER'S DEGREE

A thesis submitted in partial fulfillment of the

requirements for the degree of

MASTER OF SCIENCE

in

DIETETICS AND NUTRITION

by

Stephanie Michelle Pillow

2010 
To: Interim Dean Michele Ciccazzo

Robert Stempel College of Public Health and Social Work

This thesis, written by Stephanie Michelle Pillow, and entitled A Comparison of Job Responsibility and Activities between Registered Dietitians with a Bachelor's Degree and those with a Master's Degree, having been approved in respect to style and intellectual content, is referred to you for judgment.

We have read this thesis and recommend that it be approved.

Susan Himburg

Victoria Castellanos

Evelyn Enrione, Major Professor

Date of Defense: November 17, 2010

This thesis of Stephanie Michelle Pillow is approved.

Interim Dean Michele Ciccazzo

Robert Stempel College of Public Health and Social Work

Interim Dean Kevin O'Shea

University Graduate School

Florida International University, 2010 


\section{DEDICATION}

I wish to dedicate my thesis to my parents, my friends, my fellow students, and most of all, my husband. Without their patience, opinions, and support, I would not have been able to pursue this degree or complete my thesis. Every time I felt discouraged, they were there to provide their support or lend an ear. It truly showed me how no one can really accomplish anything alone. 


\section{ACKNOWLEDGMENTS}

I wish to thank my committee for their input, support, and most of all, their patience. I could not have asked for a better committee and truly benefited from their opinions and experience. Most of all I want to thank my major professor, Dr. Evelyn Enrione, who logged numerous hours to help me complete this monumental task. I would also like to thank the Commission on Dietetics Registration for the American Dietetic Association for allowing me to perform a more in-depth analysis of their 2005 Dietetics Practice Audit data. Last but not least, thank you to the statistics lab, Dr. Johnson, and Holli Thometz. 


\begin{abstract}
OF THE THESIS
A COMPARISON OF JOB RESPONSIBILITY AND ACTIVITIES BETWEEN

REGISTERED DIETITIANS WITH A BACHELOR'S DEGREE AND THOSE WITH
\end{abstract}

A MASTER'S DEGREE

by

Stephanie Michelle Pillow

Florida International University, 2010

Miami, Florida

Professor Evelyn Enrione, Major Professor

Minimal educational requirements for Registered Dietitians (RDs) include a bachelor's degree and practice program. Recently, a master's degree was recommended. Studies have not established whether education affects employment. A secondary analysis of 2005 Dietetics Practice Audit data determined whether job responsibility, individuals supervised, and activities differed between 1,626 bachelor's RDs (B-RDs) and 767 master's (M-RDs) RDs, registered $\leq 5$ years. Chi-square and ANOVA analyzed differences between B-RDs and M-RDs, at entry-level (0-3 years experience) and beyond-entry-level (3+-5 years experience). Beyond-entry-level B-RDs (31.8\%) and entry-level M-RDs (31.9\%) reported "supervisor/executive" responsibility more than entry-level B-RDs $(26.5 \% ; \mathrm{p}=0.01)$. A higher percentage of M-RDs supervised $(29.2 \%)$ than B-RDs $(24.7 \%$; $\mathrm{p}=0.02)$; however, B-RDs supervised more individuals $(7.38 \pm 4.89)$ than M-RDs $(6.25 \pm 4.87 ; \mathrm{t}=2.32 ; \mathrm{p}=0.021)$. A master's degree has limited benefits; experience may affect responsibility, individuals supervised, and activities more than education. 


\section{TABLE OF CONTENTS}

CHAPTER

PAGE

I.

INTRODUCTION

II.

LITERATURE REVIEW

Introduction

Role Delineation Studies

Dietetics Practice Audits

Summary of Literature Related to Current Study

III.

METHODOLOGY

Source of Data

15

Study Design

Statistical Analysis

IV.

RESULTS

Demographics

Responsibility Level of Supervisor/Executive or Staff

Directly Supervising Other People

Supervise/Manage Versus Assist Others

V.

DISCUSSION

35

Responsibility Level of Supervisor/Executive or Staff

Directly Supervising Other People

Supervise/Manage Versus Assist Others

38

Conclusions

VI. RECOMMENDATIONS

LIST OF REFERENCES 


\section{LIST OF FIGURES}

FIGURE

PAGE

1. Proportion of bachelor's and master's degree RDs who were registered for at least five years and completed the 2005 Dietetics Practice Audit

2. Percentage of RDs with a bachelor's or master's degree who reported "supervisor/executive" or "staff" as primary responsibility level and "supervise/manage" at least one activity

3. Comparison of RDs with either a bachelor or master's degree who chose "supervise/manage" or "assist others" for at least one activity statement

4. Comparison of the percentage of bachelor's and master's RDs who reported "supervise/manage" in each category

5. Comparison of the percentage of entry-level bachelor's and entrylevel master's RDs who reported "supervise/manage" in each category

6. Comparison of the percentage of bachelor's and master's RDs who reported "assist others" in each category

7. Comparison of the percentage of entry-level bachelor's and entrylevel master's RDs who reported "assist others" in each category 


\section{INTRODUCTION}

Currently, a bachelor's degree with an accredited practice program is the minimum requirement to become a Registered Dietitian (RD), but it has come under consideration that a master's degree should be the minimum requirement. The American Dietetic Association (ADA) through the House of Delegates appointed two Dietetics Education Task Forces to examine the education system in dietetics and consider the minimum requirements for entry-level practice of RDs. The members of each Task Force included ADA members, RD practitioners, and RD educators. The perspectives from those individuals currently in the field as well as the results from the recent Dietetic Practice Audits allowed the Task Forces to make informed decisions based on current information $(1,2)$. The first Task Force which began in 2003, released a final report in 2006 which indicated that it would be beneficial to increase the minimum requirements to include a master's degree. However, the meetings of the second Task Force, between 2006 and 2008, recommended concentrating on the current curriculum and the importance of lifelong learning instead of changing the existing degree needed for entrylevel practice.

While the Dietetic Practice Audits and Task Forces have examined how the profession is changing and what RDs do in their positions with respect to years of registration or experience, none have looked in-depth at entry-level RDs (0-3 years of practice) based on their educational degree $(4,6-8)$. Few studies, either prospectively or retrospectively, have included education in their surveys and none have emphasized education or educational background, in relation to job responsibilities (6-8). This has prevented linking education to activities and tasks performed by RDs in their positions. 
Therefore, it is difficult to determine what the appropriate recommendations are for the minimum education of entry-level RDs and whether to increase the requirements to include a master's degree.

The 2003 Task Force favored implementing a master's degree as the minimum degree requirement to become an $\mathrm{RD}$. Their reasoning was that increasing the educational requirements would enable the curriculum to better prepare individuals entering the field to meet the evolving needs of their future clients (1). Conversely, the 2006 Task Force did not support adding a master's degree as the minimum requirement. The second Task Force committee acknowledged that lifelong learning would be instrumental in developing the profession through specialty and advanced practice. They emphasized that continuing education and advanced degrees should be part of an RD's career, but not a requirement. Additionally, the second Task Force Report stressed the need to improve the undergraduate coursework to ensure that the entry-level RDs are able to meet the expectations of their future clients, coworkers, and supervisors (2). The Task Forces based their recommendations on the data from the Dietetics Practice Audits and opinions from their experience within the field. Discussions involving the dietetics curriculum are becoming increasingly important as the dietetics field continues to evolve and presents new responsibilities and functions for today's RDs (3). A relationship between education and job-related activities needs to be established to help determine whether education influences position or responsibility level in the workplace, how to evaluate curriculum related to practice, and where the profession needs to lead the future of practice. 
Both Task Forces examined data from recent Dietetics Practice Audits to understand what tasks RDs perform in their area of practice in dietetics $(4,6-8)$. The most recent study, the 2005 Dietetics Practice Audit, was the first to examine education level and how it affects entry-level RDs. Their investigation revealed that entry-level RDs with a bachelor's degree seem more involved in activities related to nutrition care in community and clinical settings while entry-level RDs with a master's degree tend to be more involved in activities related to education, research, marketing, and management (4). While these differences were found between the master's and bachelor's education groups in general, an in-depth analysis involving responsibility and level of involvement in activities was not performed.

The purpose of this study was to investigate if education affects the responsibility level and involvement in activities of entry-level (0-3 years of practice) and non-entrylevel (+3-5 years of practice) RDs. Data from the 2005 Practice Audit were analyzed to compare the ways RDs with a bachelor's degree are involved in activities related to their primary position to those ways RDs with a master's degree are involved.

\section{Research Questions:}

1. Are RDs with master's degrees involved in more "supervise/manage" activities than those RDs with bachelor's degrees?

2. Do RDs with bachelor's degrees report they "assist others" in more activities than those RDs with master's degrees?

3. Do RDs who reported higher levels of responsibility ("owner or partner," "executive," "director or manager," or "supervisor or coordinator") also report a 
higher level of involvement ("supervise/manage") in activities more often than those RDs who reported a lower level of responsibility ("staff")?

4. Do RDs with master's degrees directly supervise more individuals (RDs, dietetic technicians, other food/nutrition employees, and non-food/nutrition employees) than those RDs with bachelor's degrees? 


\section{LITERATURE REVIEW}

\section{Introduction}

Every profession seeks to evaluate and improve practice and education within their field and dietetics is no exception. Examining what activities individuals perform from day to day in their dietetics positions can influence training practices and educational requirements. The ADA completed several studies over the past decade and a half to determine what types of tasks RDs perform, how work is changing, and how to plan for the future education of the profession $(4,6-8)$.

These investigations, which were initially called Role Delineation Studies and now termed Practice Audits, have become routine and are completed every five years by the Commission on Dietetics Registration (CDR), the credentialing agency of the ADA. Several of these studies have examined the differences between entry-level and beyond entry-level dietetics practice $(4,6-8,11)$. The CDR defined entry-level practice as the first 3 years after registration. This definition of entry-level has been used since the second Role Delineation and for each Practice Audit and is based upon an operational definition from and has not been empirically validated (4, 6-8, 11). After searching several databases and websites (Cumulative Index to Nursing and Allied Health Literature, Nutrition Abstracts and Review, PubMed, Science Direct, National Agricultural Library Catalog, Health Science and Nursing Database, American Dietetic Association, Highwire Press, Google Scholar, National Academies Discovery Engine), it appears that CDR is the sole source of producing five studies that examine the role of the $\mathrm{RD}$ in the work place. 


\section{Role Delineation Studies}

Early comprehensive analyses of the role and responsibilities of the RD began with the Role Delineation studies in the 1980's (6, 11-13). These studies clarified the current activities and responsibilities for RDs at all levels within the field and provided a basis for credentialing standards and validating certification exams, but were also integral in determining how dietetics practice differs from one practice area to another (6-8).

The initial study, begun in 1979 and completed in 1984, divided the profession into three general areas of practice: community dietetics, foodservice systems management, and clinical dietetics (11-13). Three committees were formed to represent each area of practice and were overseen by an Advisory Committee and a Working Committee. The members were chosen for their expertise and knowledge in one of the three specific areas of practice. Each committee focused on determining which knowledge and responsibility statements were applicable to practitioners in each of these areas as well as verification of the responsibility statements as related to the profession. Each set of responsibility statements was pre-tested and condensed as needed to limit the length of the survey as well as to eliminate redundancy of similar statements. The survey was sent to random samples of RDs from the 1978 and 1979 ADA Annual Membership Survey in each of the three practice areas. A mailing of the questionnaire was completed in three stages, which included the initial survey, a follow-up letter and a second copy of the survey. Each responsibility statement within the survey included a statement and the question "Should dietetic personnel have this responsibility?" Respondents could choose: 1. no; 2. only if responsibility shared with other health providers; 3 . yes, but other health providers could have this responsibility also; 4. yes, dietetic personnel only; or 5. don't 
know. This role delineation indicated which activities RDs felt they should do/should be doing, not which activities the RDs were actually performing. This Role Delineation did not examine what percentage of the profession participated in these responsibilities or the level of involvement for the activities performed (11-13). Limited information was provided on the responses to the study instrument other than the list of responsibilities that were confirmed as related to the profession. Information on education or years of experience was collected, but not reported. Limited information was available on the process of contacting RDs and their responses to the survey. This study focused on "entry-level" within each of the three main areas of dietetics practice (clinical, community, and food service), but defined "entry-level" as one year or less of practice as opposed to the first three years of practice as in later studies" "entry-level."

A second Role Delineation in 1989 separated RDs into groups based on years of registration instead of areas of practice within the profession. The RDs surveyed were divided into entry-level (defined as registration from 0 to 3 years) and beyond-entry-level (defined as being registered more than 3 years). Five committees were assigned to this study; each focused on developing a particular aspect of the study and based their portion of the list on the information collected in the previous role delineation study's list of activities. A Job Responsibilities Committee of 12 RDs developed a list of proposed job functions and responsibilities within dietetics practice. A Knowledge Requirements Committee, which was comprised of 12 dietetic educators, developed a list of knowledge statements that would be added to the proposed list made by the Job Responsibilities Committee. In addition, three Specialty Committees focused on practice within pediatric, 
renal, and metabolic nutrition care to determine the list of responsibilities for these areas of nutrition specialty.

The lists of responsibility statements from the five committees were compiled along with the list of responsibilities from the previous Role Delineation study to create the Dietetics Practice Inventory instrument, which comprised of 129 activities RDs were believed to perform in a variety of settings. The Inventory was implemented as a survey, which was mailed to random samples of 3,559 entry-level RDs and 6,647 beyond-entrylevel RDs, as identified by the registry lists of the CDR (6). The survey procedure included four separate mailings: an introductory letter from the ADA president, the survey, a reminder postcard, and an additional copy of the survey instrument. The response rates from the samples were $77.5 \%(\mathrm{n}=2,759)$ for the entry-level RDs and 78.7\% ( $\mathrm{n}=5,233)$ for the beyond-entry-level RDs. Those RDs who reported not working in a dietetics-related position were eliminated from the sample, which left 2,500 entrylevel RDs and 3,713 beyond entry-level RDs in the analysis.

The results revealed that nearly half the entry-level RDs $(48.2 \%, n=1,197)$ and one-third of the beyond-entry-level RDs $(32.5 \%, \mathrm{n}=1,200)$ were working in "inpatientcare, acute-care" facilities. The goal of the study was to determine what functions these RDs performed in their primary position, however more than half of each group selected more than one area of work as their "primary work setting." This may have affected some of the results since a single activity may have been related to one or more "primary" positions, making it more difficult to associate a specific activity with a particular position. The survey also collected information on each RD's "role" in a given activity (“no involvement," "advising," "policy setting," "supervising," or “doing”). Beyond- 
entry-level RDs reported involvement in "administrative" and "policy-setting" roles more frequently than entry-level RDs; an example of this was that $27.9 \%$ of beyond-entry-level RDs reported preparing budgets, compared with only $14.3 \%$ of entry-level RDs. Data on educational background and education degree were not reported. (6)

\section{Dietetics Practice Audits}

After the 1989 Role Delineation, the CDR began referring to these studies as Practice Audits. The first Practice Audit in 1995 was intended to provide more current information on what RDs do and how responsibility differs among RDs in all areas of practice $(4,7,8)$. The survey instrument was based on the one from the 1989 Role Delineation. The protocol included four mailings: the survey instrument with a cover letter, a reminder postcard, a second copy of the survey, and a second reminder postcard. This study was unprecedented because in addition to surveying RDs (Practitioner Survey), employers of RDs were also surveyed on what their employees' jobs required (Employer Survey). For the Practitioner Survey, a total of 5,500 RDs were surveyed from random samples of 500 individuals from 11 different groups. From the records of CDR, ten groups were sampled based on which year an RD became registered from 1986 through 1995. The eleventh sample consisted of 500 individuals randomly selected from those registered between 1969 and 1985 (7). The overall response rate was 68\% $(n=3,761)$. Of the $68 \%$ of RDs who responded, only $84 \%(n=3,139)$ were currently employed in dietetics. Those who reported they were not employed in dietetics were excluded. The Employer Survey was sent to a separate random sample of 2,000 RDs who were registered for less than three years. They were instructed to give the survey to their employers to complete and return in the included post-marked envelope. No follow-up 
mailings were sent for the Employer Survey. The responses from the Employer Survey agreed with the responses from the practitioners in that practitioners and employers reported similar activities and areas of work for entry-level RDs. The response rate $(40 \%$, $\mathrm{n}=808$ ) was lower than for the Practitioner Survey, perhaps as a result of the indirect sampling method. This Practice Audit indicated that most RDs worked in acute-care $(44 \%, \mathrm{n}=665)$ or long-term-care $(25 \%, \mathrm{n}=305)$ settings, which was in agreement with the results from the 1989 Role Delineation (7). Additionally, the 1995 Audit suggested that the functions RDs perform are directly related to both where they work and their responsibilities. The analysis also inferred that the amount and level of responsibility was directly related to how many years the individual had been registered. Numerical data were not reported and no other possible explanations for the relationships were discussed. Information on education level was not reported; therefore, an analysis of education and responsibility or position could not be identified. (7)

The second Practice Audit performed in 2000, followed the methods of the 1995 Practice Audit and the 1989 Role Delineation with the addition of new questions and activity statements to make the information more comprehensive (8). The survey instrument included the questions from previous surveys with the addition of several new activities, for a total of 146 activity statements and questions on level of responsibility in 36 areas of practice. Random samples of 500 RDs were selected from those initially registered in 1998, 1999, and 2000 for the "entry-level" RD sample. For the "beyondentry-level" RD sample, random samples of 300 were selected from each year of those registered between 1991 and 1997 with an additional 300 individuals surveyed that were registered prior to 1991 . The survey protocol included the survey instrument, reminder 
postcards, and a second copy of the survey. A total of 3,900 RDs were sent a survey and the response rate was $63 \%(n=2,533)$. An Employer Survey was also conducted for this Audit, but had a lower response rate $(24 \%, \mathrm{n}=474)$ for employers of entry-level RDs than the 1995 study. Unlike the 1995 Audit, these RDs were separated into two groups: entrylevel RDs (registered 3 years or less) and beyond entry-level RDs (registered for more than 3 years) $(7,8)$. The data collected from the RDs were very similar to the information collected from the 1995 Audit, including that most RDs (69\% of entry-level and 63\% of beyond-entry-level) were employed in clinical positions, and about $26 \%$ of all RDs worked in a community setting (8). As with the previous audit, the data suggested an increase in responsibilities commensurate with years of experience (6-8). However, it cannot be assumed experience is the only factor which influences responsibility since different positions and settings have different requirements and activities for employees. Similar proportions were reported for levels of involvement in activities between entrylevel and beyond-entry-level RDs, but comparisons were not statistically analyzed. The 2000 Practice Audit Panel suggested that the dietetic profession had not changed significantly in the past decade because of the similarities between the 2000 Audit and the 1989 Role Delineation study (8). Educational background was not reported.

Each practice audit has built upon the earlier versions with modifications to ensure that the survey remains current and relevant to the profession $(4,7,8)$. Until the 2005 audit, the CDR collected data on RDs with different years of experience, from entry-level and beyond. The 2005 Practice Audit, however, only surveyed individuals considered entry-level to obtain a better perspective on entry-level dietetics practice (4). As in previous studies, entry-level was defined as RDs that had been registered for 3 
years or less $(4,6-8)$. The Dietetics Practice Audit Committee developed the survey instrument which built upon the previous Practice Audits and Role Delineation studies. This survey included 162 activity statements. Pre-testing and adjustments to the survey were completed to enhance validity and reliability. For the study sample, the RDs were separated into 5 groups based on how many years they had been registered from CDR's records ( 0 to 1 year, 1 to 2 years, 2 to 3 years, 3 to 4 years, and 4 to 5 years) and then 800 RDs were randomly selected from each year. A total of 4,000 surveys were mailed between May 31 and July 18, 2005. The survey protocol included four mailings: the survey, two follow-up postcards, and a second copy of the survey. Response rates for the survey were high (64\%) with a total of 1,460 RDs included in the analysis. Only RDs who had been registered for three years or less were included in the analysis. In their report, the CDR analyzed the data and separated the entry-level RDs by education level, creating two separate groups: RDs with a bachelor's degree and RDs with a master's degree.

Rogers and Fish reported that there were relatively "minor" differences between master's and bachelor's RDs with respect to entry-level practice, for example more bachelor's RDs than master's RDs reported working in in-patient acute care settings ( $80 \%$ versus $62 \%$, respectively), while more master's $\mathrm{RDs}$ reported working in educational settings (16\% versus $4 \%$, respectively) (4). The two groups were analyzed based on reported responsibility level as well as reported activities, but a comparison was not made to determine if education affected responsibility level and level of involvement in activities. 
In spite of the results from the 2005 Audit demonstrating that entry-level RDs have a variety of educational degrees (bachelor's, master's, and doctoral) and were separated by education level for portions of the study, a detailed analysis based on education level was not performed within the original study (4). Each of the Role Delineations and Practice Audit studies reported major findings that are relevant to dietetics practice; however, limited information is available on entry-level practice when examined by educational degree.

\section{Summary of Literature Related to Current Study}

The early Role Delineation studies collected data on what RDs were doing in their positions and whether certain activity statements were related to particular practice areas. These Role Delineation studies were basic and aimed at attaining categorical information, not comparisons. Within the Role Delineations, the data collected on education was not reported and information on responsibility level and level of involvement for the activities was not collected. (6)

The 1995 and 2000 Dietetic Practice Audits separated entry-level and beyondentry-level RDs within the studies, but did not compare RDs based on educational degree. Information on educational degree was not reported, making an in-depth look at RDs with respect to education not possible. The 2005 Dietetic Practice Audit was the first to include an analysis of education level data with respect to entry-level practice; therefore, no previous data is available to make a comparison with respect to education and responsibility or activities for entry-level RDs. The 2005 Dietetic Practice Audit also was limited to entry-level RDs, preventing a comparison to RDs with more experience in the original report. This study is the first to investigate entry-level RDs and their job- 
related activities with respect to their education level. This analysis will help to build a more complete picture of entry-level dietetics and the influence of education level on responsibility level and involvement in work activities. 


\section{METHODOLOGY}

\section{Source of Data}

The Commission on Dietetic Registration (CDR) of the American Dietetic Association conducted a Dietetics Practice Audit in 2005. This audit was a descriptive study to identify existing and new practice roles of RDs. The Dietetics Practice Audit Committee developed a survey instrument that built upon the 1995 and 2000 Practice Audits and the 1989 Role Delineation study (4).

The 16-page survey included three sections: Qualifications and Experience; Dietetics-Related Employment; and Activities in Your Primary Position (Appendix I). The Dietetics Practice Audit Committee developed profile questions in the Qualifications and Experience section to determine the qualifications, work experience, and type of employment of the sample. Respondents chose what type of educational degree they earned (associate's; bachelor's; master's; or doctoral) as well as the number of years and type of work experience (dietetic or non-dietetic). The second portion of the survey, the Dietetics-Related Employment section, contained specific questions on respondents' current dietetics-related employment. Respondents answered questions about their current position, employer, facility, responsibility level, and whether they supervise others. The individuals were instructed to mark how many and what type of employees they supervised (RDs, dietetic technicians, other food/nutrition employees, other nonfood/nutrition employees).

The third and final section, Activities in Your Primary Position, consisted of eleven categories (General; Principles of Education; Managing Human Resources; Marketing of Services and Products, Conducting Research; Managing Food and Other 
Material Resources; Managing Financial Resources; Managing Facilities; Community/Clinical General; Providing Nutrition Care to Individuals; and Providing Nutrition Programs for Population Groups). Each category contained a list of activities related to that particular area of practice, for a total of 162 activity statements. These statements were believed to be at the center of entry-level practice for RDs. For every activity statement, RDs could select a level of involvement (no involvement, assist others, perform myself, or supervise/manage) as well as the frequency the activity was performed (daily, weekly, monthly, or less than monthly). The participants were instructed to mark any activity they performed while working, regardless of whether it is part of their primary position or not.

The survey was pre-tested and validated for the target population of entry-level RDs through 34 cognitive interviews and pilot testing of a random sample of 200 entrylevel RDs, which resulted in subtle changes to the survey instrument (4). To obtain the study sample, the RDs from CDR's records were separated into 5 groups based on how many years they had been registered ( 0 to 1 year, $1+$ to 2 years, $2+$ to 3 years, $3+$ to 4years, and $4+$ to 5 years) and then 800 RDs were randomly selected from each year. A total of 4,000 surveys were mailed between May 31 and July 18, 2005. Four separate mailings were sent to the sample of RDs: the survey instrument, two reminder postcards, and a follow-up survey for non-respondents $(4,7,8)$. The overall response rate was $64 \%$ with a total of 2,541 completed surveys, 1,477 from entry-level RDs. The 2005 Practice Audit data were analyzed with only these parameters: current status as an RD, current employment in a dietetics position, and years of dietetics-related work experience since registration (three years or less) and those results are published elsewhere (4). 


\section{Study Design}

A secondary data analysis of the 2005 Dietetics Practice Audit was conducted to identify if education affects the responsibility level of the primary position and involvement in activities related to the primary position. The CDR granted permission to analyze the data from the 2005 Dietetics Practice Audit for this research study. The Institutional Review Board of Florida International University, Miami, FL, approved the research protocol.

\section{$\underline{\text { Sample }}$}

This study employed the same inclusion criteria as the original study (current status as an RD, current employment in a dietetics position, and three years or less of dietetics-related work experience since registration), with the addition of the individuals who reported having up to five years experience. The RDs were separated into four groups for this study: entry-level and beyond-entry-level RDs with a master's degree and entry-level and beyond-entry-level RDs with a bachelor's degree. All individuals with either a bachelor's or master's degree who responded to the survey and had been practicing for five years or less were included to compare "entry-level" (0-3 years) to those considered "beyond-entry-level" (3+-5 years).

Information to determine criteria for inclusion was taken from the "Qualifications and Experience" section. Questions associated with 1) working in a dietetics-related position, 2) educational degree earned, and 3) years of employment after becoming an RD were evaluated to determine the study sample (Appendix I).

From the section "Dietetics-Related Employment," the responsibility level of the primary position and the number of individuals the RD supervised were determined 
(Appendix I). The participants when asked "what is your primary position's responsibility level?" could choose one of the following responses: owner or partner; executive; director or manager; supervisor or coordinator; staff; or other. The options of "owner or partner," "supervisor or coordinator," "executive," and "director or manager" were grouped together as they represent a higher level of responsibility which will be referred to as "supervisor/executive." The choice of "staff" indicated a lower responsibility level. Respondents that marked "other" for their primary position's responsibility level were omitted as the actual level of responsibility could not be determined. The number and type of employee (RDs, dietetic technicians, other food/nutrition employees, other non-food/nutrition employees) each RD reported supervising was also examined.

Within the section "Activities in Your Primary Position," responses to each activity within the eleven categories were reviewed based on the "ways involved" each respondent marked (Appendix I). Responses of "supervise/manage" and "assist others" were analyzed. Activities marked "no involvement," "perform myself," or left blank were not included in the analysis.

\section{Statistical Analysis}

The responses from the 2005 Practice Audit were separated into two education groups: RDs that earned a bachelor's degree and RDs that were awarded a master's degree. The education groups were further divided based on work experience: entry-level (0-3 years experience) and beyond-entry-level ( $3+-5$ years experience). The data were analyzed with SPSS ${ }^{\circledR}$ (v. 18, SPSS, Inc., Chicago, IL) statistical software. Descriptive 
statistics, frequencies and percentages, or means and standard deviations were calculated for all variables.

\section{Primary Position Level of Responsibility}

Cross tabulations with chi-square tests compared the percentages of each of the two education groups and their reported level of responsibility ("supervisor/executive" or "staff"). The same calculations compared responsibility level between entry-level bachelor's and entry-level masters, as well as between beyond-entry-level bachelor's and beyond-entry-level master's RDs. Cross tabulations with chi-square tests compared the reported level of responsibility with the reported level of involvement (“manage/supervise” or “assist others”) between master's and bachelor's RDs.

\section{Number of Individuals Supervised}

Cross-tabulations with chi-squares compared the two education groups for the number of individuals each $\mathrm{RD}$ reported supervising. Univariate analysis of variance evaluated years of dietetic experience and number of individuals supervised between bachelor's and master's groups as well as what type of individual was supervised (RD, DTR, other food/nutrition employee, other non-food/nutrition employee).

\section{Involvement in Activities Related to Primary Position: Supervising/Managing}

\section{Versus Assisting Others}

Cross-tabulations with chi-squares were calculated between the two education groups based on the percentage of RDs who had selected "supervise/manage" on at least one of the activity statements. The same calculations were completed for RDs who had selected "assist others" on at least one of the activity statements. As within the survey, the analysis separated the activity statements by category for a total of 11 different groups 
of activities. Cross-tabulations with chi-squares determined whether a difference occurred within each activity category between education levels and choosing "supervise/manage" or "assist others" for any of the activity statements. 


\section{RESULTS \\ Demographics}

The sample included 2,393 RDs who had been registered for up to 5 years, 1,626 bachelor's RDs (67.9\%) and 767 master's RDs (32.1\%) (Figure 1). Entry-level accounted for $66.9 \%(n=1601)$ of the sample, 1,104 bachelor's RDs and 497 master's RDs.

Figure 1. Proportion of bachelor's and master's degree RDs who were registered for at least five years and completed the 2005 Dietetics Practice Audit

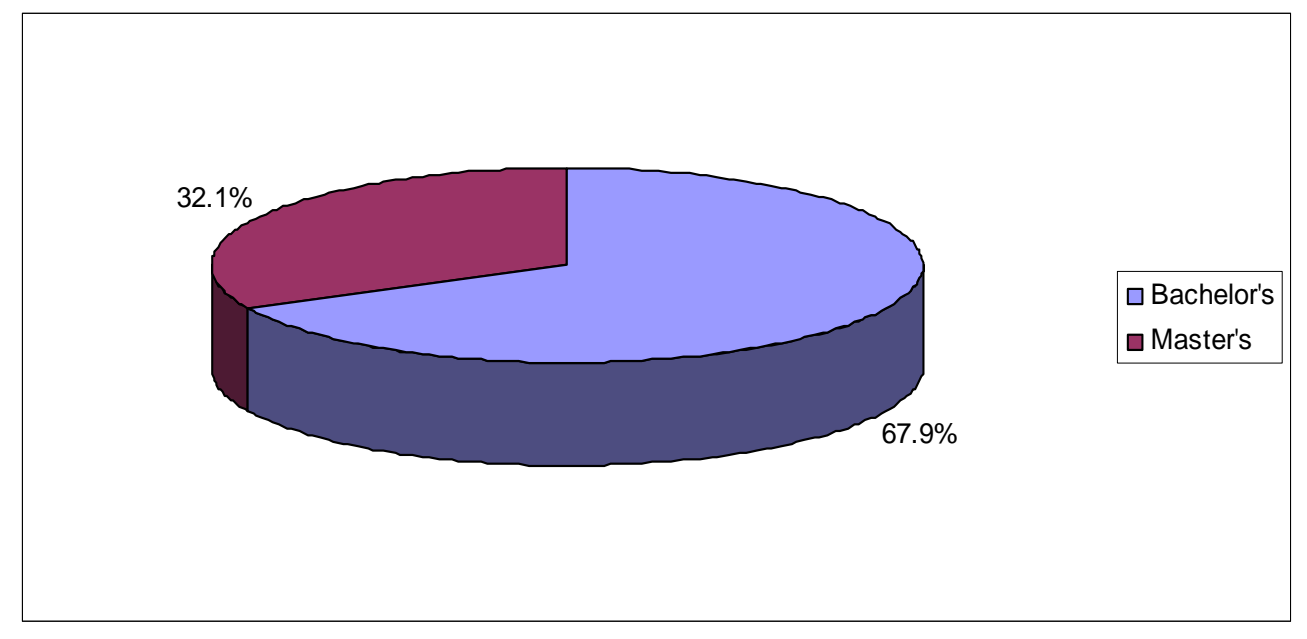

\section{Responsibility Level of Supervisor/Executive or Staff}

Of the 2,393 RDs in the sample, 25\% $(\mathrm{n}=600)$ reported "supervisor/executive" as their primary position responsibility while $63.7 \% \quad(n=1,524)$ reported "staff." Significantly more master's RDs reported "supervisor/executive" (33.4\%, n=223) when compared to bachelor's RDs $(25.9 \%, \mathrm{n}=377 ; \mathrm{p}<0.001)$.

\section{$\underline{\text { Responsibility Level and Years Experience }}$}

A significantly smaller percentage of entry-level RDs $(26.5 \%, n=377)$ chose "supervisor/executive" when compared to beyond-entry-level RDs $(31.8 \%, \mathrm{n}=223$; 
$\mathrm{p}=0.01$ ). Within the bachelor's RDs group, a significantly higher percentage of beyondentry-level RDs $(29.5 \%, \mathrm{n}=137)$ reported "supervisor/executive" than those who were entry-level RDs $(24.2 \%, n=240 ; p=0.03)$. A significant difference was not found when entry-level was compared to beyond-entry-level in the group of RDs with a master's degree who reported "supervisor/executive" $(\mathrm{p}=0.246)$. When entry-level RDs were compared, a significantly higher percentage of master's RDs $(31.9 \%, n=137)$ selected "supervisor/executive" than bachelor's RDs $(24.2 \%, \mathrm{n}=240 ; \mathrm{p}=0.01)$. No significance was found for beyond-entry-level RDs when compared by education level $(\mathrm{p}=0.069)$.

\section{$\underline{\text { Responsibility Level and Level of Involvement }}$}

Significance was found for responsibility level and level of involvement when analyzed within each of the education groups. A significantly higher percentage (67.7\%) of "supervisor/executive" reported "supervise/manage" for at least one activity when compared to RDs who reported "staff" and "supervise/manage" for at least one activity $(21.9 \% ; \mathrm{p}<0.001)$. For "staff," a significant difference was not found between the percentage of bachelor's RDs (21.7\%) and master's RDs (22.3\%) who reported "supervise/manage" for at least one activity $(\mathrm{p}=0.787)$. A significantly higher percentage of bachelor's RDs who reported "supervisor/executive" $(68.7 \%, \mathrm{n}=259)$ as their responsibility level reported "supervise/manage" for at least one activity than bachelor's RDs who reported "staff" $(21.7 \%, \mathrm{n}=234 ; \mathrm{p}<0.001)$ as their responsibility level (Figure 2). Master's RDs who reported "supervisor/executive" as their primary position's responsibility level and selected "supervise/manage" $(\mathrm{n}=147,65.9 \%)$ for at least one activity represented a significantly higher percentage than those master's RDs who reported being "staff" ( $\mathrm{n}=99,22.3 \%)$ and "supervise/manage" for at least one activity 
$(\mathrm{p}<0.001)$. For "supervisor/executive," a significant difference was not detected between the percentage of bachelor's RDs $(68.7 \%, \mathrm{n}=259)$ and master's RDs $(65.9 \%, \mathrm{n}=147)$ who reported "supervise/manage" for at least one activity $(\mathrm{p}=0.482)$.

Figure 2. Percentage of RDs with a bachelor's or master's degree who reported "supervisor/executive" or "staff" as primary responsibility level and "supervise/manage" at least one activity

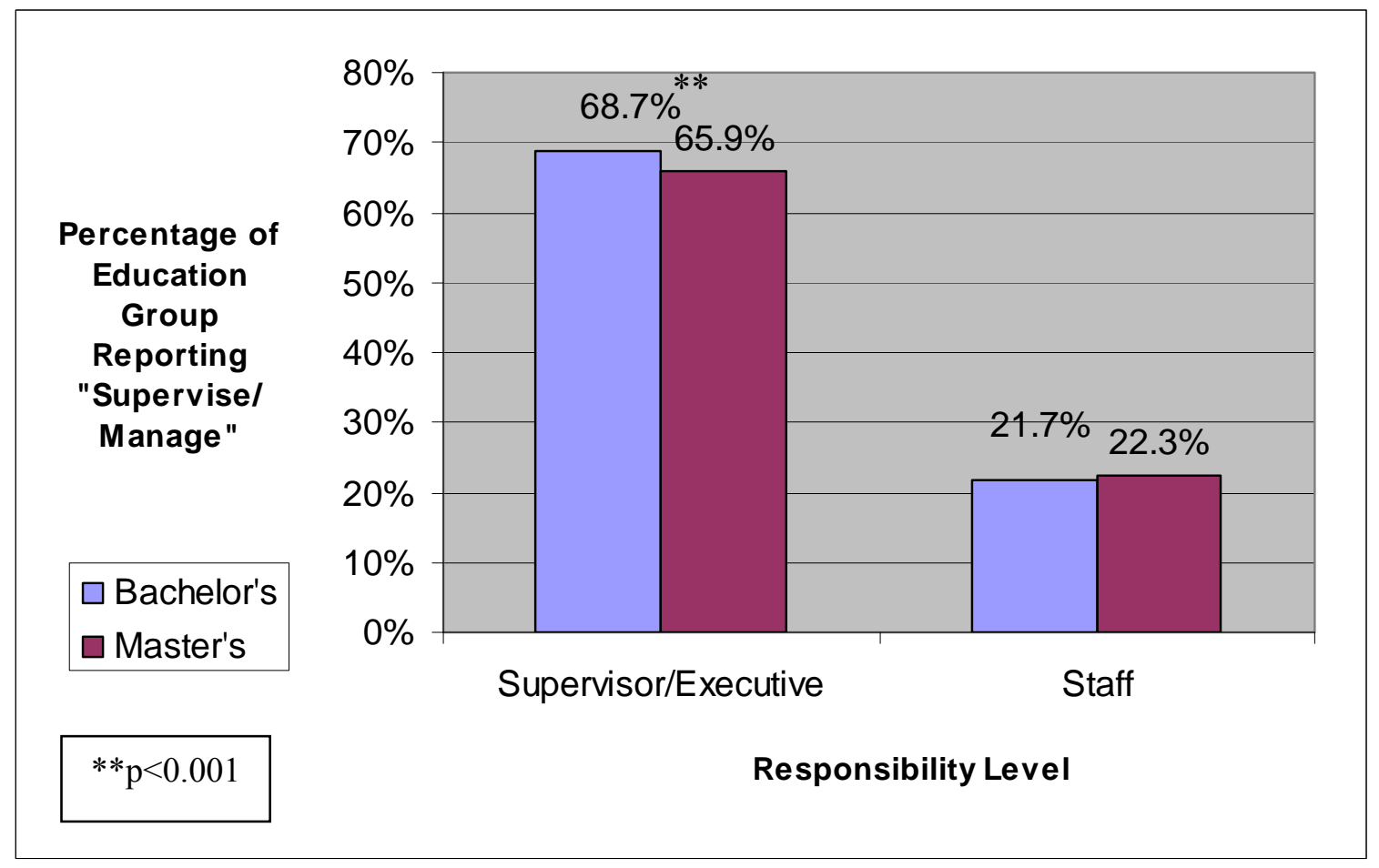

\section{Directly Supervising Other People}

The average number of individuals directly supervised by all RDs was $6.4(\mathrm{SD} \pm$ 4.75). A significantly greater percentage of master's $\mathrm{RDs}(29.2 \%, \mathrm{n}=217)$ reported 
directly supervising other people when compared to bachelor's RDs $(24.7 \%, n=392$; $\mathrm{p}=0.02)$.

\section{Supervising Other People by Education in Entry-Level}

A significantly higher percentage of entry-level master's RDs $(29.7 \%, n=141)$ indicated supervising other people when compared to entry-level bachelor's RDs $(24.3 \%$, $\mathrm{n}=261 ; \mathrm{p}=0.027$ ). A significant difference was not found in the percentages between beyond-entry-level bachelor's RDs $(33.4 \%, \mathrm{n}=131)$ and beyond-entry-level master's RDs (35.0\%, $\mathrm{n}=76)$ who reported directly supervising others $(\mathrm{p}=0.689)$. A significant difference was not detected in the percentage of entry-level RDs $(26.0 \%, \mathrm{n}=402)$ who reported directly supervising others compared to beyond-entry-level RDs who reported directly supervising others $(26.3 \%, \mathrm{n}=207 ; \mathrm{p}=0.856)$.

\section{Number of Individuals Supervised by Education Level and Years of Experience}

Bachelor's RDs report supervising a significantly higher number of total individuals (mean: 7.38, $\mathrm{SD} \pm 4.89)$ than master's RDs (mean: 6.25, $\mathrm{SD} \pm 4.87)(\mathrm{t}=2.32$; $\mathrm{p}=0.021$ ) (Table 1). A significant difference was not found in the number of individuals entry-level master's RDs (mean: 6.32, SD \pm 4.98) supervise and those entry-level bachelor's RDs (mean: 6.56, $\mathrm{SD} \pm 3.91 ; \mathrm{p}=0.624$ ) supervise. However, beyond-entrylevel bachelor's RDs reported supervising significantly more individuals (mean: 8.20, SD \pm 5.65 ) than entry-level bachelor's RDs (mean: 6.56, $\mathrm{SD} \pm 4.61, \mathrm{p}=0.001)$ (Table 1). A significant difference was not found for the average number of individuals supervised by entry-level master's RDs (mean: 6.32, $\mathrm{SD} \pm 4.98$ ) and beyond-entry-level master's RDs (mean: 6.180, $\mathrm{SD} \pm 4.61 ; \mathrm{p}=0.832$ ). 
Table 1: Average number of individuals supervised by RDs by education level and years of experience

\begin{tabular}{l|ccc}
\hline \multicolumn{1}{c|}{ Years of Experience } & Bachelor's & Master's & $\boldsymbol{p}^{\text {-valu }} \mathbf{p}^{2}$ \\
\hline Entry-Level & $6.56 \pm 3.91^{1}$ & $6.32 \pm 4.98$ & 0.624 \\
Beyond-Entry-Level & $8.20 \pm 5.65$ & $6.18 \pm 4.61$ & 0.003 \\
\hline Total & $\mathbf{7 . 1 1} \pm \mathbf{4 . 6 2}$ & $\mathbf{6 . 2 7} \pm \mathbf{4 . 8 4}$ & $\mathbf{0 . 0 0 7}$ \\
\hline
\end{tabular}

${ }^{\mathrm{T}}$ Means \pm SD (all values)

${ }^{2}$ Analysis of variance for equivalence between groups

Number of Individuals Supervised Separated by Type of Employee

When the employees supervised were separated into each specific type (RDs, DTRs, other food/nutrition employees, and other non-food/nutrition employees), few differences emerged. Bachelor's RDs reported directly supervising more "other food/nutrition employees" (mean: 6.88, $\mathrm{SD} \pm 3.33$ ) than master's RDs (mean: 6.02, $\mathrm{SD} \pm$ $3.69 ; \mathrm{p}=0.007$ ) reported supervising. No significance was found for the number of RDs $(p=0.438)$, DTRs $(p=0.965)$, and "other non-food/nutrition employees" $(p=0.968)$ supervised by either education group.

\section{Supervise/Manage Versus Assist Others}

A significant difference was not found between master's RDs $(n=275,35.9 \%)$ and bachelor's RDs ( $\mathrm{n}=544,33.5 \%)$ who chose "supervise/manage" for one or more activity statements $(\mathrm{p}=0.249)$ (Figure 3$)$. However, a significantly higher percentage of bachelor's RDs reported "assist others" ( $\mathrm{n}=1453,89.4 \%)$ for at least one activity statement when compared to the master's RDs $(n=657,85.7 \% ; p=0.009)$ (Figure 3). 
Figure 3. Comparison of RDs with either a bachelor or master's degree who chose "supervise/manage" or "assist others" for at least one activity statement

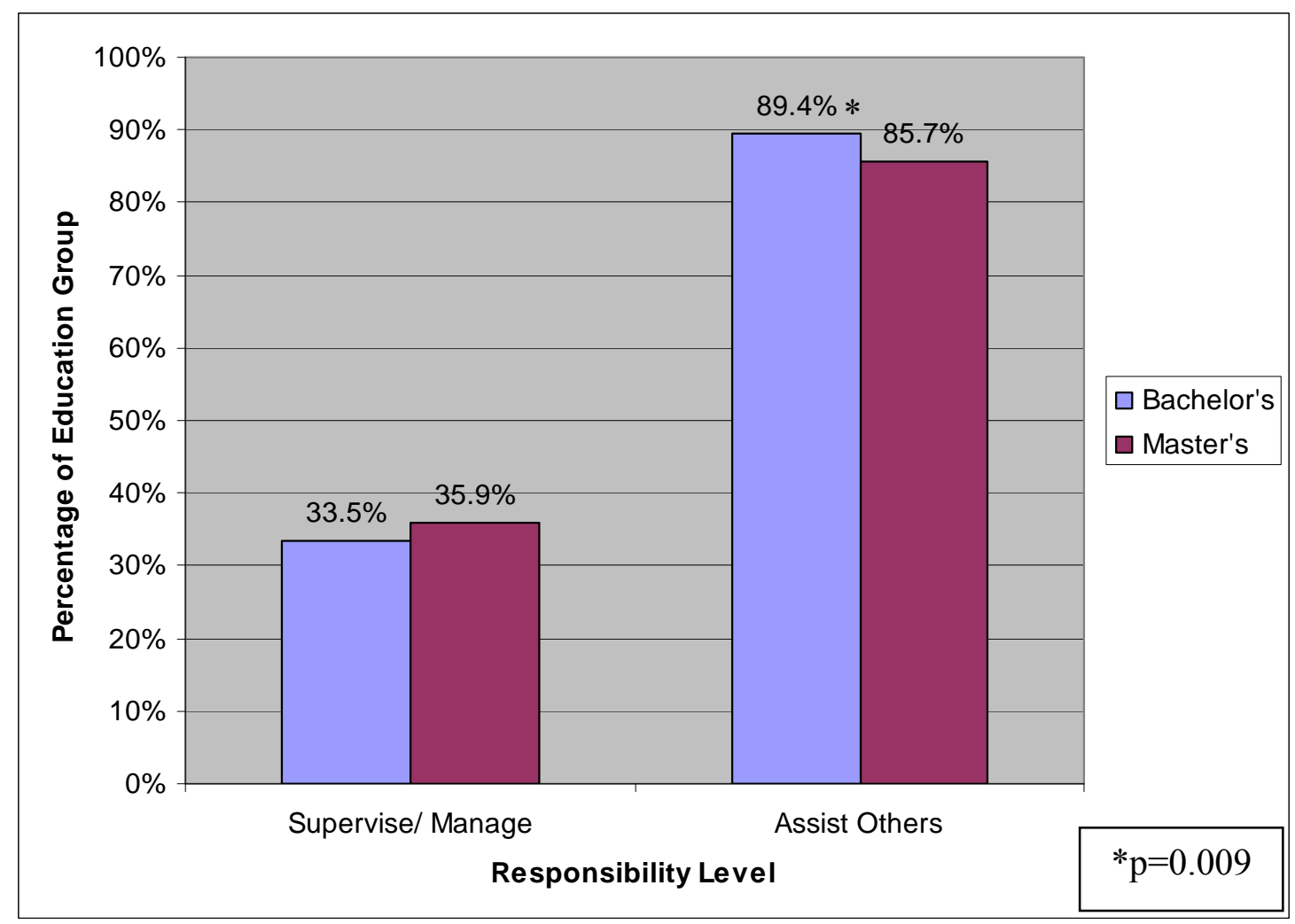

\section{$\underline{\text { Comparison of Education Level and Years Experience in Supervise/Manage }}$}

\section{$\underline{\text { Activities }}$}

When the sample was separated into entry-level and beyond-entry-level, some significant differences were found. Among bachelor's RDs, a significantly higher percentage of beyond-entry-level RDs $(38.5 \%, \mathrm{n}=201)$ reported "supervise/manage" than entry-level RDs $(31.1 \%, \mathrm{n}=343)$ for at least one activity statement $(\mathrm{p}=0.003)$. No significant difference was found for "supervise/manage" when entry-level and beyondentry-level master's RDs were compared $(p=0.615)$. A significant difference was not found between entry-level bachelor's RDs and entry-level master's RDs for 
"supervise/manage" $(\mathrm{p}=0.101)$. No significant difference was found when beyond-entrylevel bachelor's RDs and beyond-entry-level masters RDs who reported "supervise/manage" for at least one activity statement were compared ( $\mathrm{p}=0.686)$.

Comparison of Education within Each Category for Supervise/Manage Activities

In the "general" group of activities, significantly more master's RDs ( $\mathrm{n}=194$, $25.3 \%)$ reported "supervise/manage" than bachelor's RDs ( $\mathrm{n}=324,19.9 \% ; \mathrm{p}=0.003)$ (Figure 4). A comparison within the "principles of education" category revealed that significantly more master's RDs (n=131, 17.1\%) reported "supervise/manage" than bachelor's RDs ( $\mathrm{n}=225,13.8 \%$; $\mathrm{p}=0.038$ ) (Figure 4). In the "managing human resources" category, significantly more master's RDs (n=105, 13.7\%) reported "supervise/manage" than bachelor's RDs $(\mathrm{n}=172,10.6 \% ; \mathrm{p}=0.026)$. Within the "marketing services and products" grouping, significantly more master's RDs $(\mathrm{n}=63,8.2 \%)$ reported "supervise/manage" than bachelor's RDs ( $\mathrm{n}=83,5.1 \%$; $\mathrm{p}=0.003)$. A significantly smaller percentage of bachelor's RDs ( $\mathrm{n}=19,1.2 \%)$ in the "conducting research" category reported "supervise/manage" than master's RDs $(n=21,2.7 \% ; \mathrm{p}=0.005)$. The percentage of master's RDs ( $\mathrm{n}=65,8.5 \%)$ who reported "supervise/manage" in the "providing nutrition care for population groups" category was significantly higher than bachelor's RDs ( $\mathrm{n}=85,5.2 \% ; \mathrm{p}=0.001$ ) (Figure 4). No significant difference was found between RDs with a bachelor's degree and master's degree in the "managing food and other resources" $(\mathrm{p}=0.500)$, “managing financial resources" $(\mathrm{p}=0.140)$, “managing facilities" $(\mathrm{p}=0.355)$, "community/clinical general" ( $\mathrm{p}=0.188$ ), or "providing nutrition care to individuals" categories $(\mathrm{p}=0.392)$ (Figure 4$)$. 
Figure 4. Comparison of the percentage of bachelor's and master's RDs who reported “supervise/manage" in each category

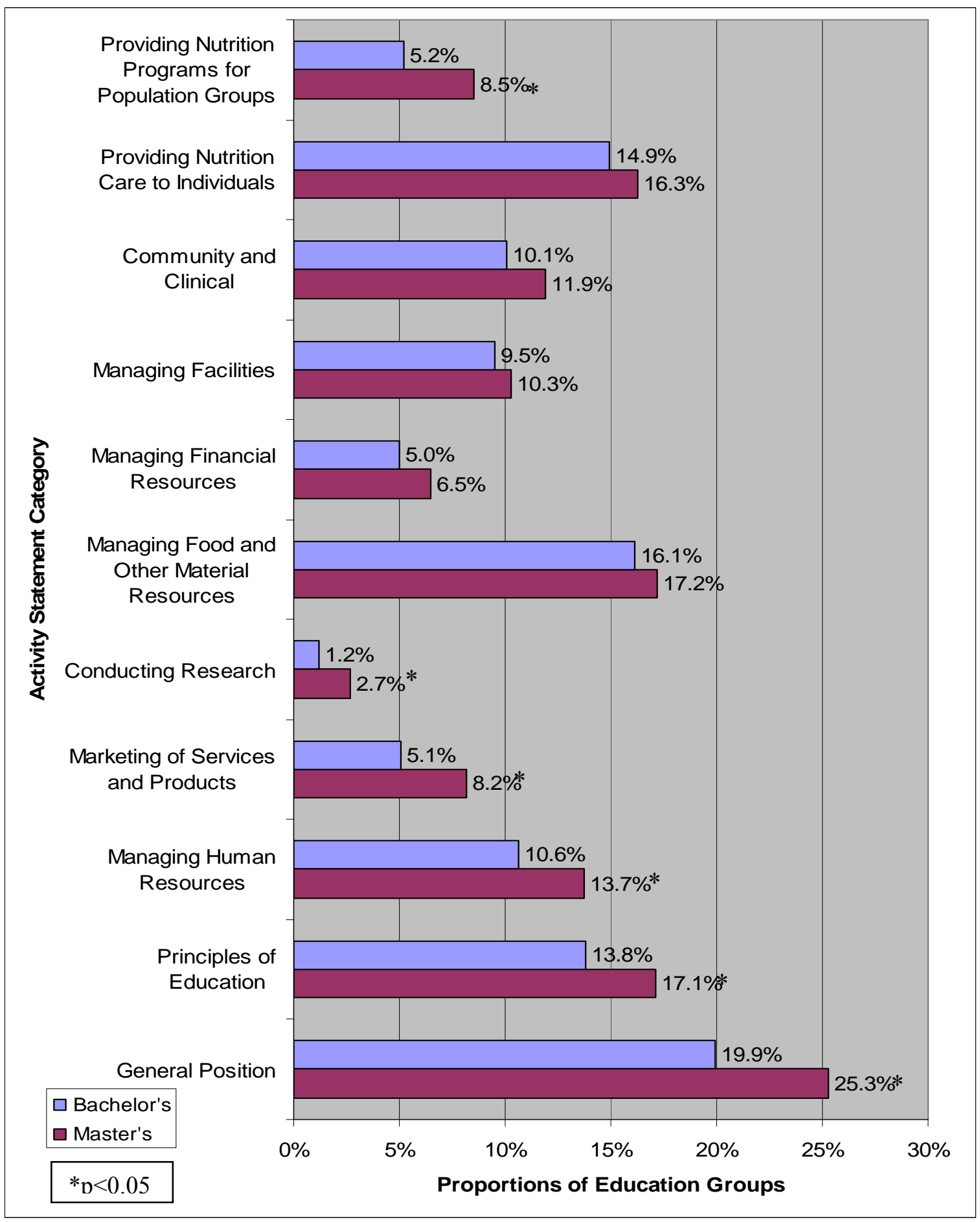




\section{Supervise/Manage by Category Among Entry-Level Separated by Education}

$\underline{\text { Level }}$

Several differences were found when an analysis was done of only the entry-level RDs within the sample with regard to "supervise/manage." Within the "general" category, a significantly higher percentage of entry-level master's RDs $(24.7 \%, \mathrm{n}=123)$ reported "supervise/manage" than entry-level bachelor's RDs $(17.7 \%, n=195 ; p=0.001)$ (Figure 5). A significantly higher percentage of entry-level master's RDs $(16.7 \%, \mathrm{n}=83)$ reported "supervise/manage" than entry-level bachelor's RDs $(12.5 \%, 138)$ within the "principles of education" category $(\mathrm{p}=0.024)$. Within the "managing human resources" category, significantly more master's RDs $(13.1 \%, \mathrm{n}=65)$ reported "supervise/manage" than bachelor's RDs $(8.8 \%, \mathrm{n}=97 ; \mathrm{p}=0.008)$. A significantly higher percentage of master's RDs $(7.2 \%, \mathrm{n}=36)$ reported "supervise/manage" than bachelor's RDs $(4.2 \%$, $\mathrm{n}=46 ; \mathrm{p}=0.010)$ in the "marketing of services and products" category. A significantly higher percentage of master's RDs $(2.8 \%, \mathrm{n}=14)$ reported "supervise/manage" than bachelor's RDs $(1.0 \%, \mathrm{n}=11)$ in the "conducting research" category $(\mathrm{p}=0.007)$. A significantly higher percentage of entry-level master's RDs $(7.8 \%, n=39)$ reported "supervise/manage" than entry-level bachelor's RDs $(4.4 \%, \mathrm{n}=49)$ within the "providing nutrition programs for population groups" category $(\mathrm{p}=0.006)$. No significant difference was found in the "managing food and other resources" ( $p=0.369)$, the "managing financial resources" $(p=0.387)$, "managing facilities" $(p=0.574)$, “community/clinical general" $(\mathrm{p}=0.188)$, or "providing nutrition care to individuals" categories $(\mathrm{p}=0.205)$ when compared to entry-level by education group (Figure 5). 
Figure 5. Comparison of the percentage of entry-level bachelor's and entry-level master's RDs who reported "supervise/manage" in each category

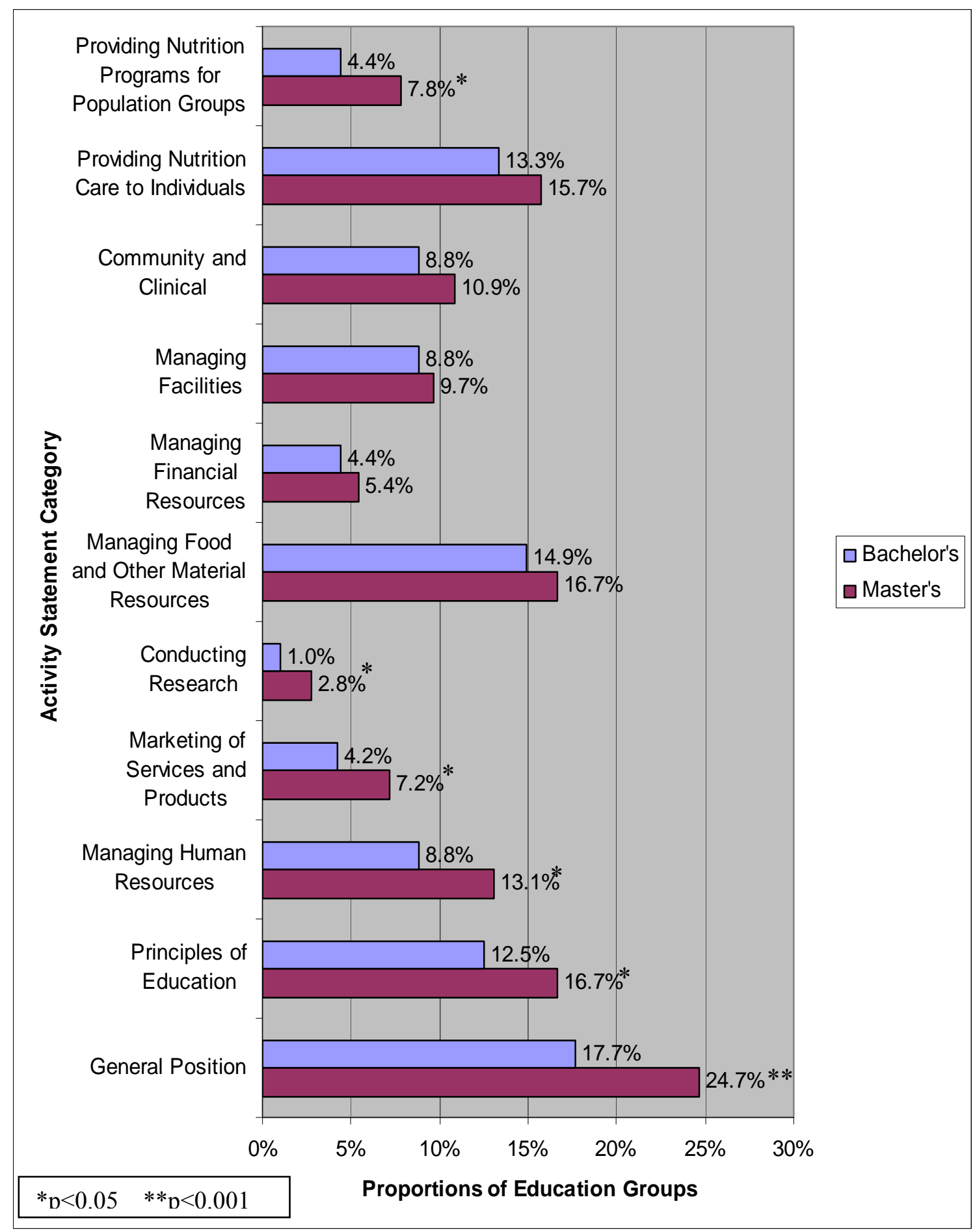




\section{Comparison of Education within Each Category for Assist Others Activities}

A significantly higher percentage of master's RDs $(n=122,15.9 \%)$ reported "assist others" within the "conducting research" category than bachelor's RDs (n=166, 10.2\%), $(\mathrm{p}<0.001)$ (Figure 6). Nearly half of bachelor's RDs $(\mathrm{n}=766,47.1 \%)$ reported "assist others" in the "managing food and other resources" category, while significantly fewer master's RDs reported they "assist others" ( $n=317,41.3 \%),(p=0.008)$ (Figure 6). A significantly higher proportion of bachelor's RDs $(n=499,30.7 \%)$ reported "assist others" in the "managing facilities" category when compared to master's RDs ( $\mathrm{n}=195$, $25.4 \%),(p=0.008)$. A significantly higher percentage of bachelor's RDs $(n=886,54.5 \%)$ reported "assist others" in the "providing nutrition care to individuals" than master's RDs $(\mathrm{n}=355,46.3 \%),(\mathrm{p}<0.001)$. Choosing "assist others" was not significantly different between the education groups in the "general" $(\mathrm{p}=0.134)$, "principles of education" $(p=0.767)$, "managing human resources" $(p=0.674)$, "marketing of services and products" $(p=0.833)$, "managing financial resources" $(p=0.161)$, "community/clinical general" category $(\mathrm{p}=0.138)$, or "providing nutrition care for population groups" categories $(p=0.866)$ within the survey (Figure 6). 
Figure 6. Comparison of the percentage of bachelor's and master's RDs who reported "assist others" in each category

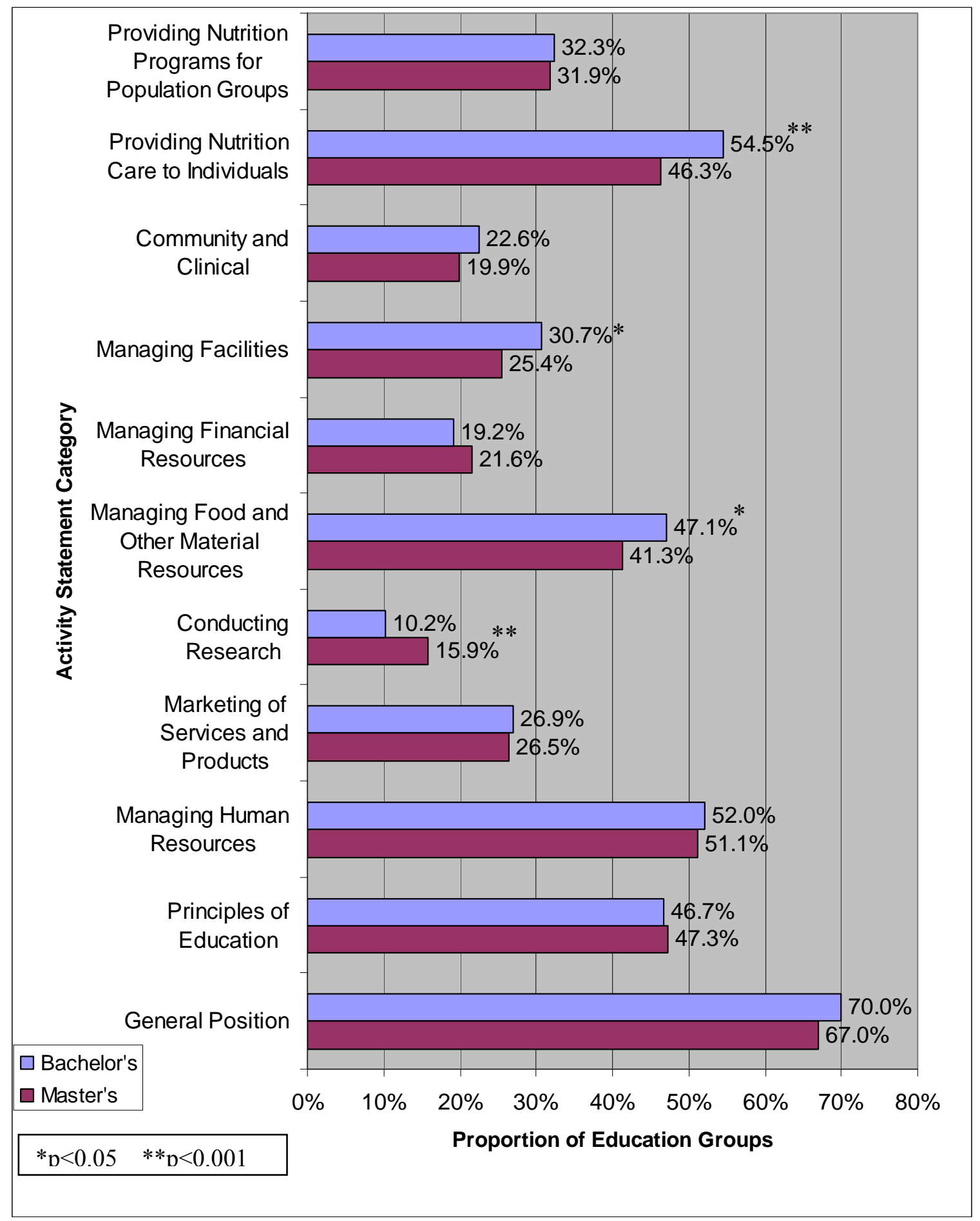




\section{Assist Others by Category Separated by Entry-Level and Education Level}

Several differences were found when an analysis was completed of only the entrylevel RDs within the sample with regard to "assist others." A significantly higher proportion of entry-level master's RDs $(14.9 \%, \mathrm{n}=74)$ reported "assist others" within the "conducting research" category than entry-level bachelor's RDs $(9.6 \%, n=106 ; p=0.002)$ (Figure 7). Within the "managing facilities" category, a significantly higher percentage of entry-level bachelor's RDs $(30.9 \%, n=341)$ reported "assist others" than entry-level master's RDs $(24.7 \%, \mathrm{n}=123 ; \mathrm{p}=0.012)$. A significantly higher proportion of entry-level bachelor's RDs $(54.4 \%, \mathrm{n}=601)$ reported "assist others" than entry-level master's RDs $(46.9 \%, \mathrm{n}=233)$ within the "providing nutrition care to individuals" category $(\mathrm{p}=0.005)$. No significance was found for the "general" $(p=0.216)$, "principles of education" $(\mathrm{p}=0.681)$, "managing human resources" $(\mathrm{p}=0.521)$, "marketing of services and products" $(\mathrm{p}=0.597)$, "managing food and other resources" $(\mathrm{p}=0.051)$, "managing financial resources" $(\mathrm{p}=0.723)$, “community/clinical general" $(\mathrm{p}=0.119)$, or "providing nutrition programs for population groups" categories $(\mathrm{p}=0.234)$ (Figure 7$)$. 
Figure 7. Comparison of the percentage of entry-level bachelor's and entry-level master's RDs who reported "assist others" in each category

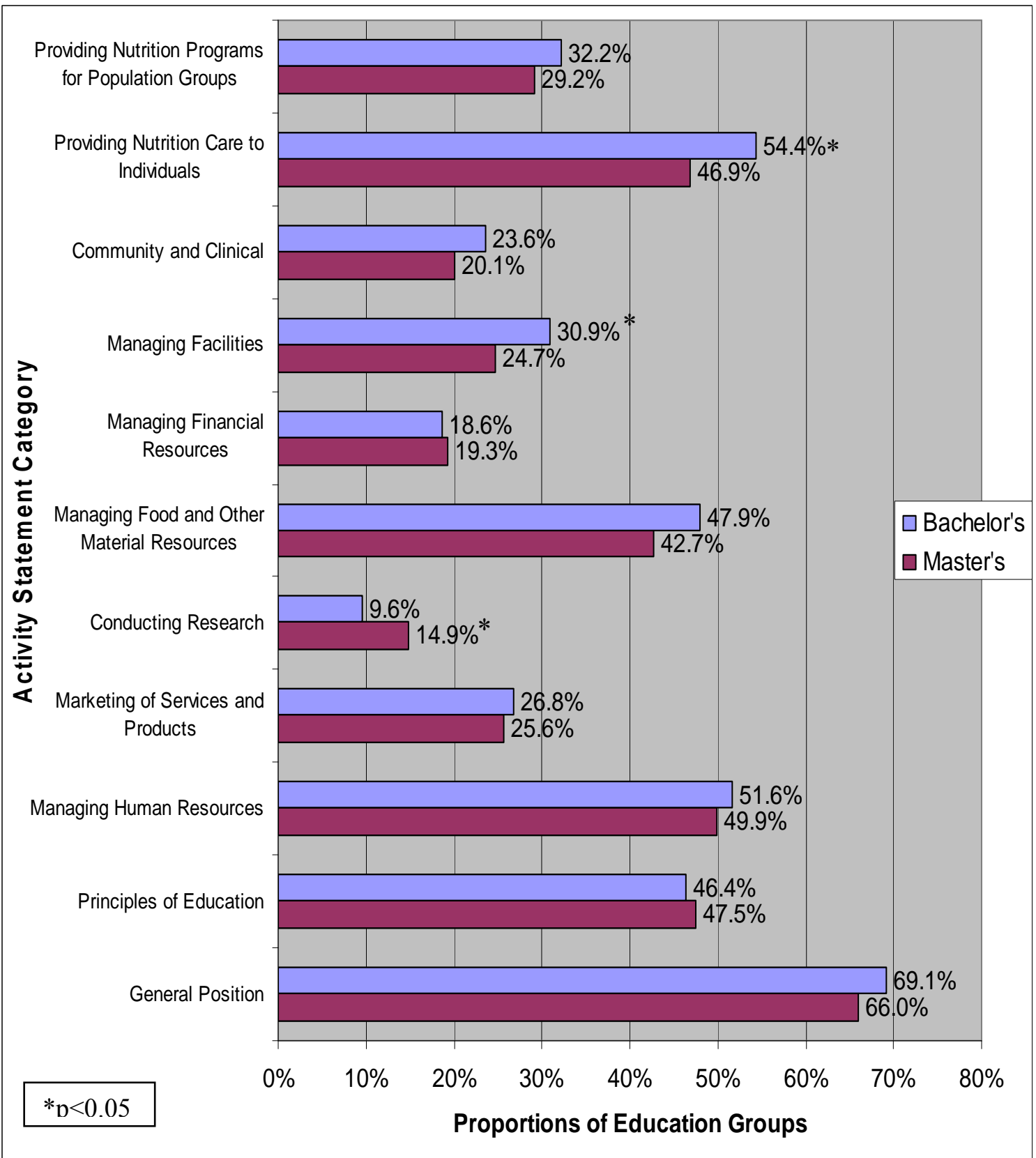




\section{DISCUSSION}

The findings indicated that education level may have an influence over what activities an entry-level RD performs and the ways they are involved in work-related activities. One study has examined the effect of education on dietetics practice, and none have analyzed and reported this relationship within entry-level practice (4). Data from the 2005 Dietetics Practice Audit suggests that education level has little effect on entry-level dietetics practice (4). A secondary analysis from that practice audit provides insight into primary job responsibility level and involvement in job activities of bachelor's and master's RDs. However, years of experience may have more influence over primary position level of responsibility for beyond-entry-level RDs than education level.

\section{Responsibility Level of Supervisor/Executive or Staff in Primary Job}

Responsibility level for master's RDs only vary in some respects from their bachelor's RD counterparts. Higher percentages of both RD education groups reported "staff" than reported "supervisor/executive" for their primary job responsibility level. Only one-quarter of the sample reported "supervisor/executive," which indicates that the majority of RDs work in "staff" positions the first five years of their career. However, beyond-entry-level master's and bachelor's RDs, master's RDs, and entry-level master's RDs reported "supervisor/executive" as their primary position responsibility level at comparable rates $(29.5 \%, 33.4 \%$, and $31.9 \%$, respectively), while entry-level bachelor's RDs had fewer individuals reporting "supervisor/executive" (24.2\%). This suggests that years of experience and education level may have a similar influence in responsibility

level. Responsibility level appears to increase with years of experience for bachelor's RDs; however, education seems to allow master's RDs to have a higher level of 
responsibility at the entry-level. Advanced education may move an individual into a position of more responsibility at entry-level, while those without advanced education must accrue years of experience to move into the same position.

The bachelor's and master's RDs who reported "supervisor/executive" as the responsibility level in their primary job were more likely to report "supervise/manage" for one or more activity statements than those RDs who reported "staff" as their responsibility level. Responsibility level in a primary job is associated with level of involvement in work activities as evidenced by the high percentage of RDs who reported higher responsibility levels also reported a higher level of involvement in activities (67.7\%). However, more than $20 \%$ of those who reported "staff" as their responsibility level also reported a higher level of involvement in work activities ("supervise/manage"). It is unknown what factors cause RDs in "staff" positions to perform activities that involve "supervise/manage." Primary position, type and size of the facility, and other work-related factors (for example: the number of RDs employed or the presence of an interdisciplinary team) which were not examined in this study could also affect the level of involvement in job activities for individuals who reported "staff" positions.

\section{Directly Supervising Other People}

When the number of individuals supervised was compared between bachelor's and master's RDs, the results did not indicate a master's degree was advantageous. A larger percentage of master's RDs reported supervising one or more individuals than bachelor's RDs reported. However, when the education groups were divided into years of experience (entry-level versus beyond-entry-level), only entry-level was significant. More entry-level master's RDs reported directly supervising people than bachelor's RDs, 
but a difference was not found between beyond-entry-level master's and beyond-entrylevel bachelor's RDs. This suggests that master's RDs may have more supervisory responsibilities at entry-level, but that the advantage of a higher degree is equal to years of experience beyond entry-level.

Although more master's RDs reported they supervise people, bachelor's RDs reported supervising more total individuals and the number supervised increased in the beyond-entry-level bachelor's group. The reported number of individuals supervised for entry-level master's RDs and entry-level bachelor's RDs did not differ significantly, but the number did increase for bachelor's RDs from entry-level to the beyond-entry-level group. Years of experience appear to cause an increase in the number of individuals supervised by bachelor's RDs, but it may be that primary position and the type and size of a facility have an influence on how many individuals an RD supervises.

Although differences were found for the number of individuals supervised between education groups, the type of individual supervised only differed for one group. Bachelor's RDs reported supervising more "other food/nutrition employees;" however, other types of employees (RDs, DTRs, and other non-food/nutrition employees) had no significance. Other factors, such as primary job position or care setting, may have more influence over the type of employees supervised than education level. The size and type of facility would be a limiting factor in the number and type of individuals available for an RD to supervise, additionally, the number of other RDs employed by the facility may positively or negatively affect reported levels of other employees supervised. 


\section{Supervise/Manage Versus Assist Others}

The instructions for the survey were clear on the definitions of "supervise/manage" as "oversee performance of this activity by others and/or plan, organize, or direct organizational performance of this activity" and "assist others" as "help with this activity under someone else's direct supervision" (Appendix I). This would imply that an RD in a higher-level position should report "supervise/manage" more often than those in lower-level positions as well as RDs in lower-level positions should be more likely to report "assist others" than those in higher-level positions (4). It may explain why a choice of "supervise/manage" had a stronger relationship to higher responsibility level than lower responsibility level. A difference was not found for the number of RDs who reported "supervise/manage" for one or more activity statements in their primary job between education groups. However, bachelor's RDs reported “assist others" for at least one activity statement more often than master's RDs. Years of experience may have caused the percentage of bachelor's RDs who reported "supervise/manage" to increase from entry-level to beyond-entry-level, but did not have any significant effect on master's RDs between the entry-level and beyond-entry-level groups. Education level may increase the level of involvement in work activities at entrylevel, but years of experience has an equalizing effect past the first three years of practice.

When the activity statements were analyzed within the 11 categories of the survey, master's RDs were more likely to report "supervise/manage" for activity statements and bachelor's RDs were more likely to report "assist others" for activity statements in most activity categories. Since more master's RDs reported a higher level 
of involvement in activity statements related to their primary positions, it may indicate that the involvement in activities may be influenced by their master's degree. Another possibility is that the RDs who responded to the survey may have assisted individuals of other professions (for example, physicians) during certain activities; however, the survey did not include a way to specify who the RD assisted and a comparison could not be made. Reports have discussed professional partnerships within dietetics practice, which may influence job responsibilities and level of involvement in activities (15). It is possible that working with individuals of other professions causes master's and bachelor's RDs to report a different level of involvement in some activities dependent on whom they are supervising or assisting. For example working with a physician to "recommend intravenous or parenteral nutrition therapies" may cause an RD to report a lower level of involvement ("assist others"), while working with a new DTR to "take preliminary diet histories" may cause an RD to report a higher level of involvement (“supervise/manage").

Significantly more master's RDs reported "supervise/manage" within most activity categories (general, principles of education, managing human resources, marketing services and products, conducting research, providing nutrition care to population groups) than bachelor's RDs. When entry-level was compared, master's RDs reported "supervise/manage" at significantly higher rates than bachelor's RDs in the same activity categories as the comparison between education groups. Years of experience may not influence the level of involvement for master's RDs in these particular activity categories and their advanced degree allows them to have a higher level of involvement in these activities. 
Bachelor's RDs reported "assist others" more frequently than master's RDs in most activity categories, except for "conducting research" where significantly more master's RDs reported “assist others.” This may indicate that master's RDs are being hired for research positions to help other master's or doctoral RDs more than bachelor's RDs. Master's-prepared RDs have more skills related to research as part of their degree, while bachelor's RDs have likely not developed these skills to the same level. Within some categories (conducting research, principles of education, and managing human resources), responses of "supervise/manage" or "assist others" may be an effect of the type of position these activity levels fall within and do not necessarily demonstrate that master's RDs have an advantage. For example "Serve as preceptor or supervise students" within the "principles of education" category should be more likely to have a higher reported level of involvement than "Collect data used in research studies" within the "general" activity category.

Reported level of involvement for the activity categories had similar results when entry-level was examined for "assist others." The one category that differed significantly between groups was "managing food and other resources," which had significance for bachelor's RDs who reported "assist others" but did not have significance for bachelor's RDs at entry-level. The categories that were not statistically significant may indicate that education or years of experience do not provide an advantage with respect to level of involvement in those activities related to the primary position.

\section{$\underline{\text { Strengths and Limitations of the Study }}$}

Given the large sample size, the sample from the survey is representative of the population during the time period of the original study and increased the validity and 
reliability of this secondary data analysis. Since this study was a secondary analysis, the data were limited to information the CDR collected during the 2005 Dietetics Practice Audit. The results from this analysis can only describe the entry-level and beyond-entrylevel RDs at the time the survey was conducted and cannot describe the current population. An inherent limitation to secondary data analyses is the survey instrument of the primary study. Responses were limited to questions in the survey and little opportunity was given to the respondents to expand upon the given set of questions in the original study. The respondents were not able to list the individuals they "supervise/manage" or "assist others" for activity statements. Additional activity statements that were not included in the survey and added by respondents did not include a place to specify the ways the RDs were involved. Information was not collected on the size of the facility or the number of other RDs employed by the facility where respondents worked, which may have affected level of responsibility and level of involvement in job-related activities.

\section{Conclusions}

An analysis of the involvement of work-related activities and primary position responsibility level of bachelor's and master's RDs at entry-level and beyond-entry-level was conducted. The results provide moderate to minimal support of the theory that a master's degree may be beneficial as the entry-level degree. Some dietetics positions (for example, conducting research) may benefit from a master's degree while others do not (for example, general clinician). A recent study by Rigby-Koutz, et al, suggested that RDs with a master's degree feel that they have some benefit from their advanced degree in their primary positions, but no studies empirically show that a master's degree has any 
true influence (17). It is unclear when the RDs from the 2005 Dietetics Practice Audit completed their master's degree (before their RD, simultaneously with their RD, or after their RD) and what affect the time of completion had on the responsibility level of their primary position, the ways they are involved in their work activities, and the individuals they supervise.

The data from the secondary analysis suggest that the benefits are dependent upon the types of job-related activities as well as the responsibility level of the RD. The results also indicate that years of experience may have more influence over the level of involvement in activities and responsibility level than education, especially beyond entrylevel. Further study is needed to determine if the differences between master's RDs and bachelor's RDs are affected in other ways, such as how often they perform activities, their primary position's practice setting, or knowledge acquired through continued education credits (16). Since the dietetics profession is continually evolving, it is essential to understand what positions and activities are associated with entry-level and beyond at both the bachelor's and master's degree level, particularly with regard to managerial and supervisory roles. 


\section{RECOMMENDATIONS}

This research provided information to assist in determining whether it is beneficial for RDs to have a master's degree at entry-level and may provide a baseline for other studies to determine any significant changes in the future for each degree with respect to activities and primary position responsibility at entry-level and beyond. Based on the findings of the current analysis, the next step for future studies should include:

1. Investigating the specific tasks these entry-level RDs and beyond-entrylevel RDs perform in their primary jobs as related to the activity statement categories. This would help determine whether the activity categories are related to certain primary positions and whether they differ between the education groups. This may show that while entry-level and beyond-entrylevel RDs hold similar positions, their daily activities may differ between a bachelor's and master's degree in the field today.

2. Examining the other levels of involvement for the activity statements ("no involvement" or "perform myself") within the 2005 Dietetics Practice Audit survey as related to educational background. These other levels of involvement could show a more significant difference between RDs by education level or years of experience.

3. Examining whether work-related activities and responsibility level are affected by when RDs complete/completed their master's degree (before their $\mathrm{RD}$, simultaneous with their $\mathrm{RD}$, or after their $\mathrm{RD}$ ). A recent study explored whether RDs thought they had any benefit in their positions according to when they obtained their master's degree, but no study has 
examined whether it affects the activities RDs perform or their responsibility level (17).

4. Determining what entry-level is and whether the current definition (the first three years of practice) is appropriate. Given the variety of educational degrees RDs possess (bachelor's, master's, and doctoral) and the different routes to attain a master's degree (before $\mathrm{RD}$ status is attained, concurrent with $\mathrm{RD}$ status, or after $\mathrm{RD}$ status was attained) it may be necessary to distinguish between different "entry-level" groups by education. Competency studies have been done, but do not compare or examine education level (18). 


\section{LIST OF REFERENCES}

1. American Dietetic Association. Dietetics Education Task Force Final Report and Recommendations. July 10, 2006.

2. American Dietetic Association. Final Report of the Phase 2 Future Practice and Education Task Force. July 15, 2008.

3. Maillet J, Skates J, Pritchett E. American Dietetic Association: Scope of dietetics framework. J Am Diet Assoc. 2005; 105:634-640.

4. Rogers D, Fish JA. Entry-Level Dietetics Practice Today: Results from the 2005 Commission on Dietetic Registration entry-level dietetics practice audit. $J$ Am Diet Assoc. 2006; 106:957-964.

5. Touger-Decker, M. Advanced practice doctorate in clinical nutrition: A new graduate degree option for registered dietitians. Top Clin Nutr. 2005. 20; 1: 48-53.

6. Kane M, Estes C, Colton D, Eltoft C. Role delineation for dietetic practitioners: Empirical results. J Am Diet Assoc. 1990; 90:1124-1133.

7. Kane M, Cohen A, Smith E, Lewis C, Reidy C. 1995 Commission on Dietetic Registration dietetics practice audit. J Am Diet Assoc. 1996. 96 (12): 1292-1301.

8. Rogers D, Leonberg B, Broadhurst C. 2000 Commission on Dietetic Registration dietetics practice audit. J Am Diet Assoc. 2002. 102 (2): 270-292.

9. American Dietetic Association. Dietetics Education and the Needs for the Future: Executive Summary of HOD Backgrounder Dietetics Education and the Needs for the Future. 2003.

10. Byham-Gray L. Research reports for practitioners: A review of the "body" and the "backbone" for the dietetics profession. Top Clin Nutr. 2005; 20(1):2-15.

11. Role Delineation and Verification for Entry-Level Positions in Community Dietetics. Chicago, IL: American Dietetic Association: 1983.

12. Role Delineation and Verification for Entry-Level Positions in Foodservice Systems Management. Chicago, IL: American Dietetic Association; 1983.

13. Role Delineation and Verification for Entry-Level Positions in Clinical Dietetics. Chicago, IL: American Dietetic Association; 1984.

14. American Dietetic Association. Report to the House of Delegates Council on Future Practice. Fall 2009. 
15. White J, Bielak K, Rogers E, Lennon E. Professional partnerships: Key to dietetics practice success. Top Clin Nutr. 2003; 18(4):221-228.

16. Tougher-Decker R. Developing a continuum for lifelong learning in dietetics. Top Clin Nutr. 2002; 17(3):1-9.

17. Rigby-Koutz J, Touger-Decker R, Brody R, et al. The perceived benefits of master's degrees in two samples of registered dietitians. Top Clin Nutr. 2010; 25(3):202-212.

18. Gilmore C, O'Sullivan Maillet J, Mitchell B. Determining educational preparation based on job competencies of entry-level dietetics practitioners. J Am Diet Assoc. 1997; 97(3):306-316. 
Appendix 


\section{CDR \\ COMMISSION ON DIETETIC REGISTRATION \\ the credentialing agency for the American Dietetic Association}

\section{Dietetics Practice Audit}

This Practice Audit is part of a comprehensive study of dietetics practice being conducted by the Commission on Dietetic Registration to identify existing and new practice roles and to delineate competencies needed to succeed in the marketplace. In order to obtain a complete picture of dietetics practice today, it is important that responses from everyone selected for the sample be included.

We are interested in obtaining information about your practice situation if you currently are (or have recently been) employed or self-employed in a dietetics-related position: that is, a position that requires or makes use of your education, training, and/or experience in dietetics or nutrition, including positions that may not be considered traditional dietetics practice. As long as your position has some tasks that are relevant to dietetics, we ask that you complete the audit.

1a. Are you currently employed or self-employed in one or more dieteticsrelated positions (as defined above)?

$\square$ yes, 1 position

$\square$ yes, 2 or more positions ... if you checked "yes", please skip to Question \#3 on next page $\square$ no

1b. If no, have you been employed or self-employed in a dietetics-related position since you became registered?

$\square$ yes ... if you checked "yes", please skip to Question \#3 on next page

$\square$ no

2. If you answered "no" to both Question \#1a and Question \#1b, what is your current employment status?

(please 3 all that apply)

$\square$ currently employed or self-employed in a non-dietetics-related position

$\square$ not employed - at home raising a family

$\square$ not employed — seeking dietetics employment

$\square$ not employed — seeking non-dietetics employment

$\square$ not employed — student 
$\square$ not employed — for other reasons

a. If you are currently employed or self-employed in a non-dieteticsrelated position, what is your position title and its major responsibilities?

title

responsibilities

\section{Your qualifications and experience}
3. In what year were you born?
19

4. What degree(s) have you earned?

(please 3 all that apply)

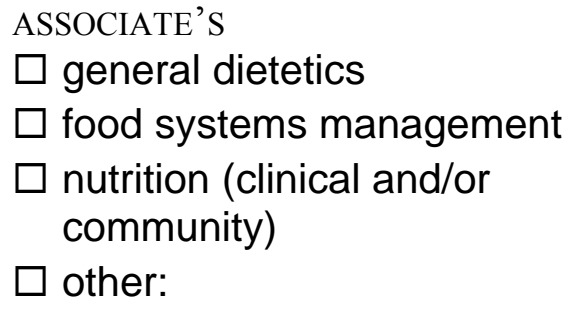

$\square$ general dietetics

$\square$ food systems management

$\square$ nutrition (clinical and/or community)

other:

BACHELOR'S

$\square$ general dietetics

$\square$ food systems management

$\square$ nutrition (clinical and/or community) other:
MASTER'S

$\square$ general dietetics

$\square$ food systems management

$\square$ nutrition

$\square$ community/MPH

$\square$ other:

DOCTORAL

$\square$ general dietetics

$\square$ food systems management

$\square$ nutrition

$\square$ community/DrPH

$\square$ other:

\section{Are you currently enrolled in a degree program?}


$\square$ yes ... if yes, indicate degree and field of study:

degree (AA, BS, etc.)

$\square$ no

field of study

6. What state dietetics practice licenses or state certifications do you currently hold (if any)?

(please 3 all that apply)

$\square$ state licensed/state certified dietitian ... in what state(s)?

state licensed/state certified technician ... in what state(s)?

none

7a. What dietetics registration credentials do you currently hold (if any)? (please 3 the one best option)

$\square$ RD (Registered Dietitian) $\quad \square$ both

$\square$ DTR (Dietetic Technician, $\quad \square$ neither Registered)

7b. What other professional credentials do you currently hold (if any)? (please spell out full name of credentials)

8. Is dietetics a second career for you?

$\square$ yes $\square$ no

9. Approximately how many years of work experience do you have in each of these categories?

(if none fill in 0; please use decimals for fractional parts of a year, e.g., 0.5 for $1 / 2$ year)

\#

dietetics-related employment prior to becoming registered as an $\mathrm{RD}$

years

(INCLUDING dietetic internship) 
\#___ other employment (not dietetics-related) prior to becoming registered

years as an RD (excluding summer jobs, jobs during school, etc.)

\#___ dietetics-related employment after becoming registered as an $\mathrm{RD}$

years

\section{Your dietetics-related employment}

If you answered "no" to both Question \#1a and Question \#1b on page 1, the rest of this audit will not apply to you — please skip to Question \#25 on the final page.

If you have been employed or self-employed in a dietetics-related position since registration but are not now (answered Question \#1a "no" and Question \#1b "yes"), answer for your most recently held dietetics-related position.

If you are currently employed or self-employed in more than one dietetics-related position, answer for the one you consider to be your primary dietetics-related position.

10a. What is the full job title of your primary position?

10b. Please carefully review the enclosed list of Position Descriptions. Which one description most closely matches your primary position (even if your job title differs)? (fill in the 3-character code found next to the position title - A01, B10, etc.)

11. Is this the first dietetics-related position you have held since becoming registered as an RD?

$\square$ yes $\quad \square$ no ... if you checked "no", please skip to Question \#12 below

a. If no, how many other dietetics-related positions have you held since becoming registered?

$\square 1$ other position

$3-4$

$\square 2$

5 or more

12. How many years have you worked in your primary position?

(please use decimals for fractional parts of a year, e.g., 0.5 for $1 / 2$ year)

\#___years 
13a. Is your primary position full-time, part-time, or per diem?
full-time
part-time
per diem

13b. How many hours are there in a standard work week for this position? If self-employed, how many hours typically worked?
$\square 40$ hours
35 hours
$\square$ other:
$\square 37.5$ hours
$\square 30$ hours

14a. Is this a year-round position?
yes
no

14b. Is this a permanent or a temporary position?
permanent
temporary

15a. Is registration as an RD a requirement for employment in this position?

$\square$ registration is required

$\square$ registration is preferred but not required

$\square$ registration makes no difference

15b. Are any other credentials or licenses required for employment in this position?

$\square$ no

$\square$ yes, state license/certification

$\square$ yes, other (please specify):

16. Which one option best matches the nature of your employer in your primary position? (please check the one best option)
$\square$ self-employed
$\square$ not-for-profit
$\square$ for-profit
$\square$ government

17. In your primary position, in what setting(s) and practice area(s) do you spend AT LEAST $20 \%$ of your time?

Please check NO MORE THAN 5 boxes!

PRACTICE AREA 


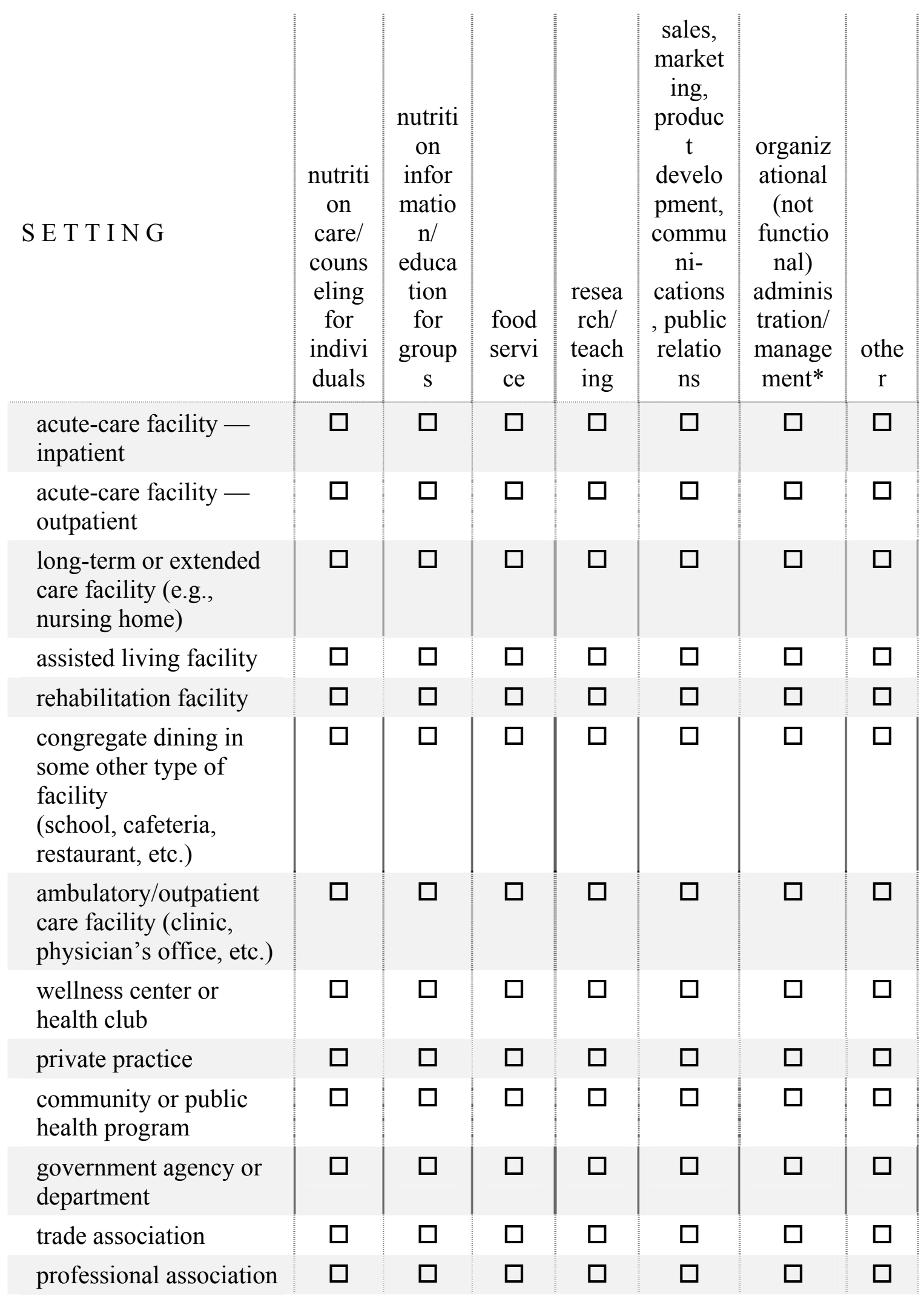


college, university, or

teaching-hospital

faculty

food manufacturer, distributor, or retailer

pharmaceutical or nutrition products manufacturer, distributor, or retailer other

please specify:

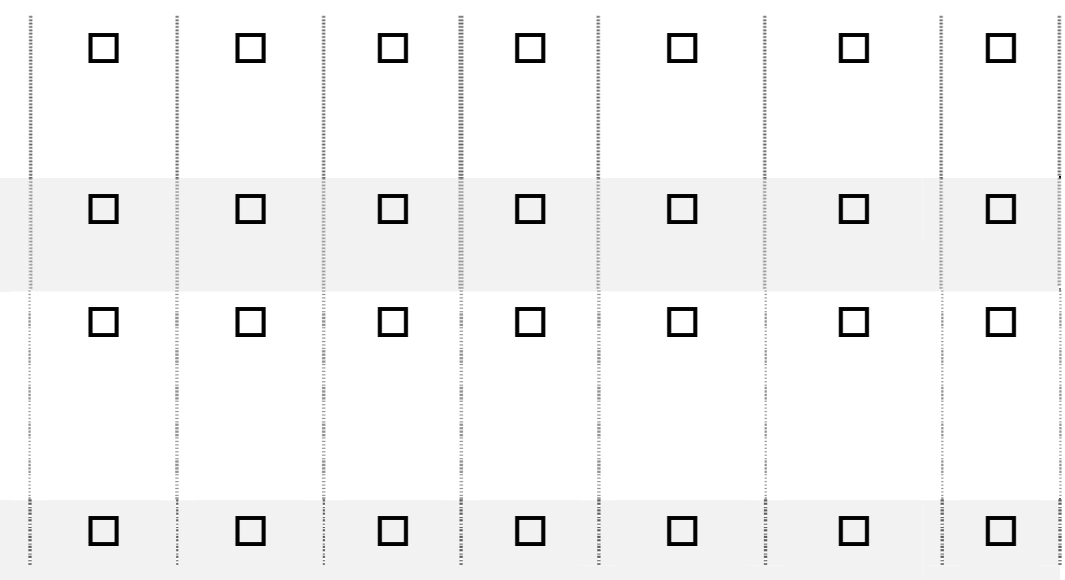

$-$

* Please $\checkmark$ "organizational administration/management" only if your management responsibilities are not tied to a specific functional area - for example, if you are manager of a food service operation, record your answers under "food service", not under "organizational administration/management".

18. What is your primary position's responsibility level?
owner or partner
executive
supervisor or coordinator
director or manager
staff
$\square$ other:

19. In your primary position, do you directly supervise other people?

$\square$ yes $\square$ no ... if you checked "no", please skip to Question \#20 below

a. If yes, how many other people in each of these categories do you directly supervise (if any)?

(please 3 one box on each line)
none $\quad \begin{array}{lllll}1 & 2 & 3-4 & 5-9 & 10+\end{array}$

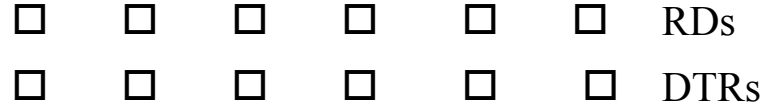
$\square \quad \square \quad \square \quad \square \quad \square \quad \square$ other food/nutrition employees

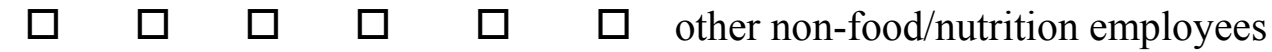

\section{b. Are any of the people you supervise from outside of your department or work unit? \\ yes \\ no \\ does not apply}


20. In your primary position, are you responsible for managing one or more budgets?

$\square$ yes $\quad \square$ no ... if you checked "no", please skip to Question \#21

below

a. If yes, approximately what is the total annual amount of the budget(s) you are responsible for?
$\square$ less than $\$ 10,000$
$\$ 500,000$ - $\$ 999,999$
$\square 10,000-\$ 49,999$
$\$ 1$ to $\$ 2.49$ million
$\$ 50,000-\$ 99,999$
$\$ 2.5$ to $\$ 4.99$ million
$\$ 100,000$ - $\$ 499,999$
$\$ 5$ million or more

21. Which of these options apply to your immediate supervisor? (please 3 all that apply)
$\square$ DTR
$\square \mathrm{MD}$
$\square \mathrm{RD}$
$\square$ facility administrator
RN
none of these
food service director

\section{Activities in your primary position}

This section asks about a large number of activities which might or might not be part of the primary dietetics-related position you are reporting on. To develop the fullest possible picture of how dietetics is practiced today, it is important that you carefully read and respond to each activity — do not assume that whole sections do not apply to your position.

For each activity, two questions are asked:

In the last year, in what way(s) have you been involved with this activity no involvement assist others help with this activity under someone else's direct supervision perform myself supervise/manage personally do this activity (independently or as part of a group) without direct supervision

(if any)? oversee performance of this activity by others and/or plan, organize, or direct organizational performance of this activity

( $\checkmark$ all that apply)

[IF INVOLVED] How frequently have you been personally involved (in any way) with this activity over the last year? ( $\checkmark$ the one best option)

daily 
weekly

monthly

less than

monthly

\section{EXAMPLES}

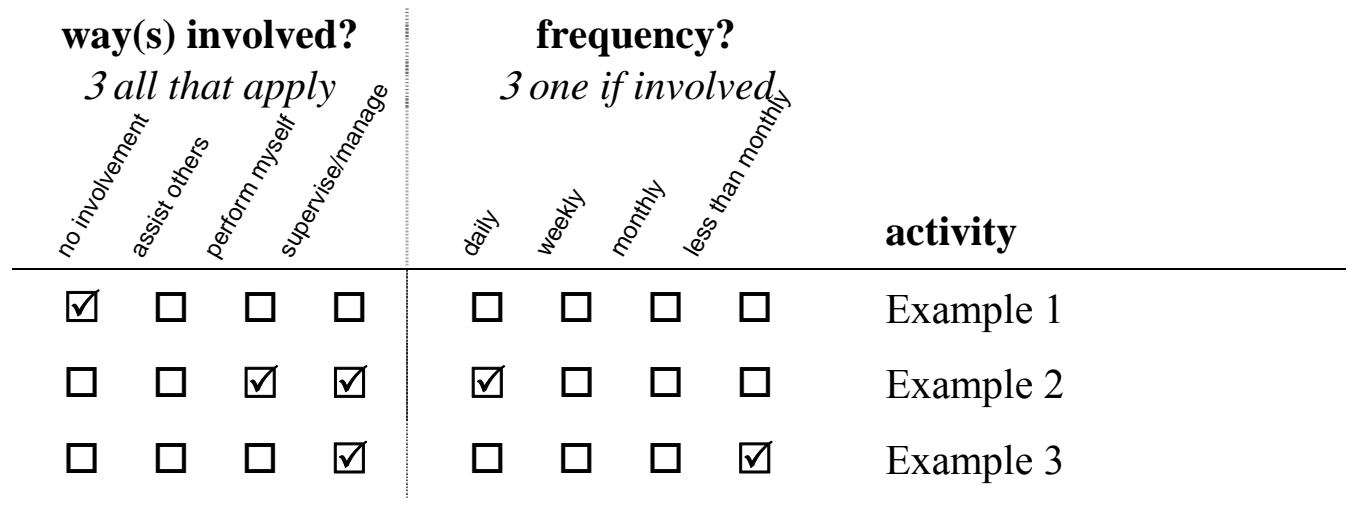

Example 1 represents an activity you have not been involved with in the past year in your primary position, so no involvement is checked for way(s) involved, and no other responses are required.

Example 2 represents an activity that you generally supervise but also frequently perform yourself, so both perform myself and supervise/manage are checked for way(s) involved. You are involved with this activity several times a day, performed by you or under your supervision, so daily is checked for frequency.

Example 3 represents an activity which others reporting to you either supervise or perform themselves, and for which you have organizational responsibility. Therefore, supervise/manage is checked for way(s) involved. This activity occurs only twice each year, so less than monthly is checked for frequency.

Please carefully read and respond to each activity — do not assume that whole sections do not apply to your position.

\section{Activities in your primary position: general}

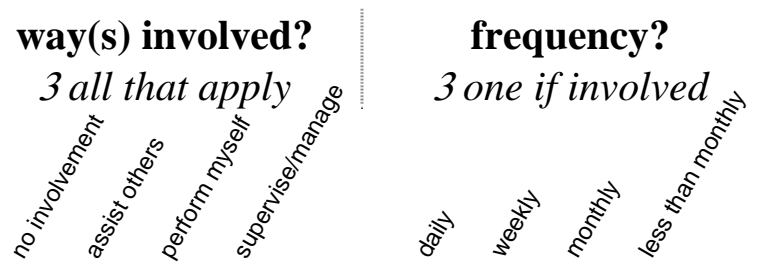




\section{activity}

\begin{tabular}{|c|c|c|c|c|c|c|c|c|}
\hline$\square$ & $\square$ & $\square$ & $\square$ & $\square$ & $\square$ & $\square$ & $\square$ & $\begin{array}{l}\text { Evaluate how effective programs are } \\
\text { in reaching } \\
\text { their goals }\end{array}$ \\
\hline$\square$ & $\square$ & $\square$ & $\square$ & $\square$ & $\square$ & $\square$ & $\square$ & $\begin{array}{l}\text { Adapt products/services to fit the } \\
\text { market }\end{array}$ \\
\hline$\square$ & $\square$ & $\square$ & $\square$ & $\square$ & $\square$ & $\square$ & $\square$ & Develop new products/services \\
\hline$\square$ & $\square$ & $\square$ & $\square$ & $\square$ & $\square$ & $\square$ & $\square$ & Collect data used in research studies \\
\hline$\square$ & $\square$ & $\square$ & $\square$ & $\square$ & $\square$ & $\square$ & $\square$ & $\begin{array}{l}\text { Collect data for clinical and/or } \\
\text { management decisions }\end{array}$ \\
\hline$\square$ & $\square$ & $\square$ & $\square$ & $\square$ & $\square$ & $\square$ & $\square$ & $\begin{array}{l}\text { Evaluate and synthesize research } \\
\text { literature using a formal method }\end{array}$ \\
\hline$\square$ & $\square$ & $\square$ & $\square$ & $\square$ & $\square$ & $\square$ & $\square$ & Analyze data \\
\hline$\square$ & $\square$ & $\square$ & $\square$ & $\square$ & $\square$ & $\square$ & $\square$ & Write reports \\
\hline$\square$ & $\square$ & $\square$ & $\square$ & $\square$ & $\square$ & $\square$ & $\square$ & $\begin{array}{l}\text { Use evidence analysis as the basis for } \\
\text { practice decisions; e.g., evidence- } \\
\text { based guidelines or practice, evidence } \\
\text { analysis library, and/or position papers }\end{array}$ \\
\hline$\square$ & $\square$ & $\square$ & $\square$ & $\square$ & $\square$ & $\square$ & $\square$ & Negotiate contracts \\
\hline$\square$ & $\square$ & $\square$ & $\square$ & $\square$ & $\square$ & $\square$ & $\square$ & Delegate tasks \\
\hline$\square$ & $\square$ & $\square$ & $\square$ & $\square$ & $\square$ & $\square$ & $\square$ & $\begin{array}{l}\text { Perform quality assurance, quality } \\
\text { improvement, or performance } \\
\text { improvement (QA/QI/PI) }\end{array}$ \\
\hline
\end{tabular}

\section{Activities in your primary position: principles of education}

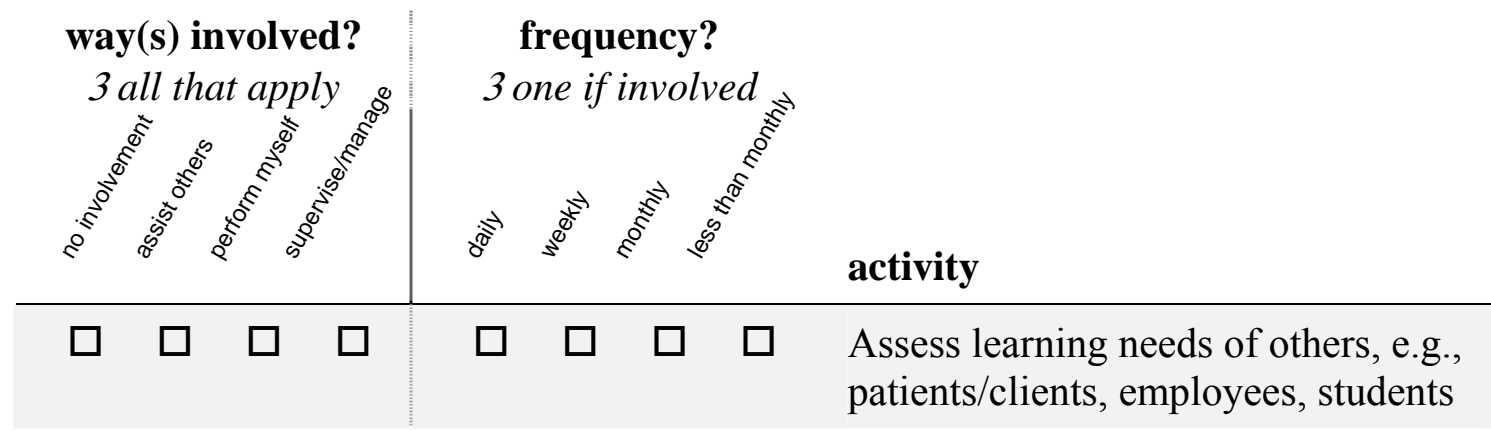




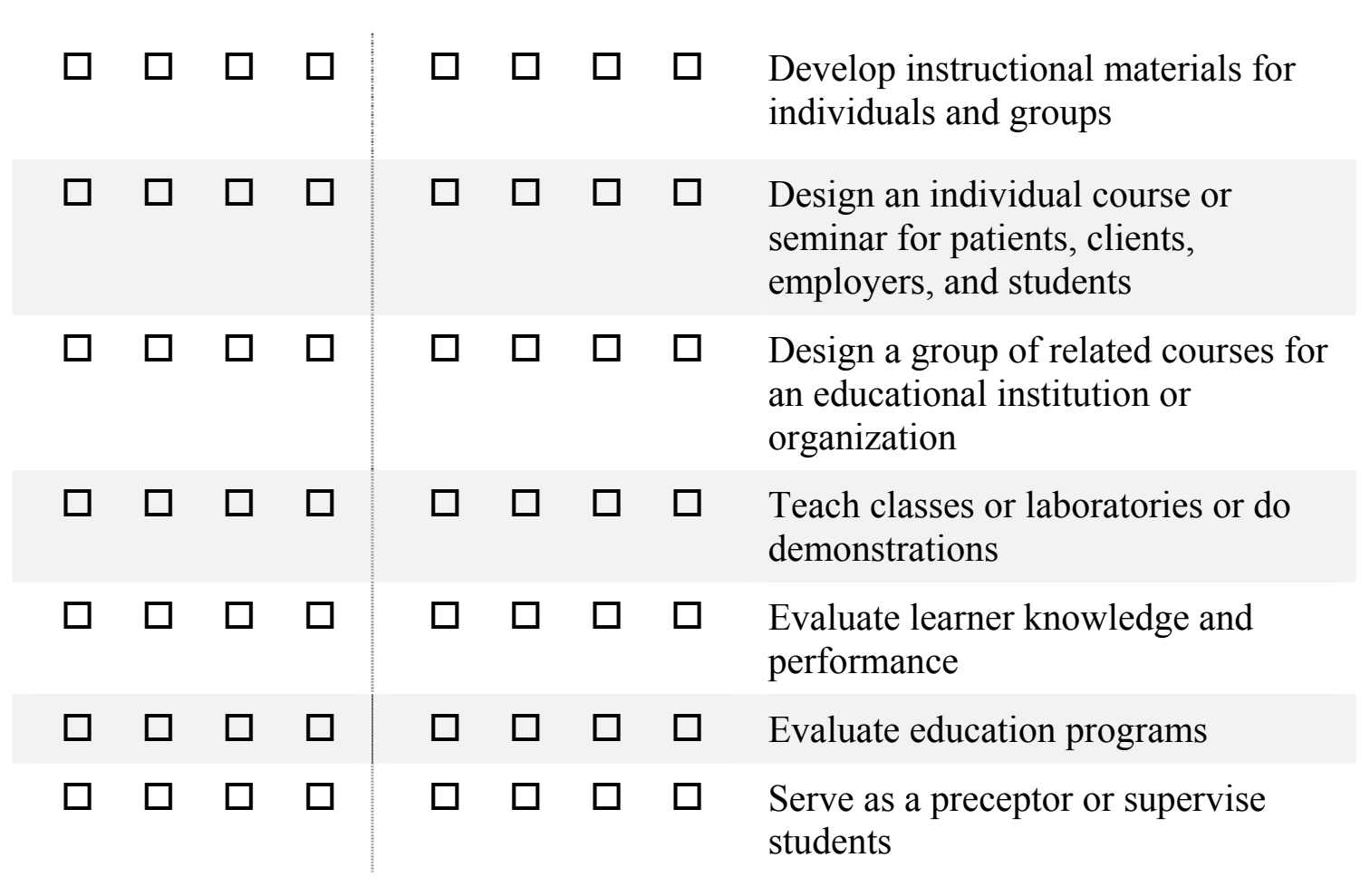

Please carefully read and respond to each activity — do not assume that whole sections do not apply to your position.

\section{Activities in your primary position: managing human resources}

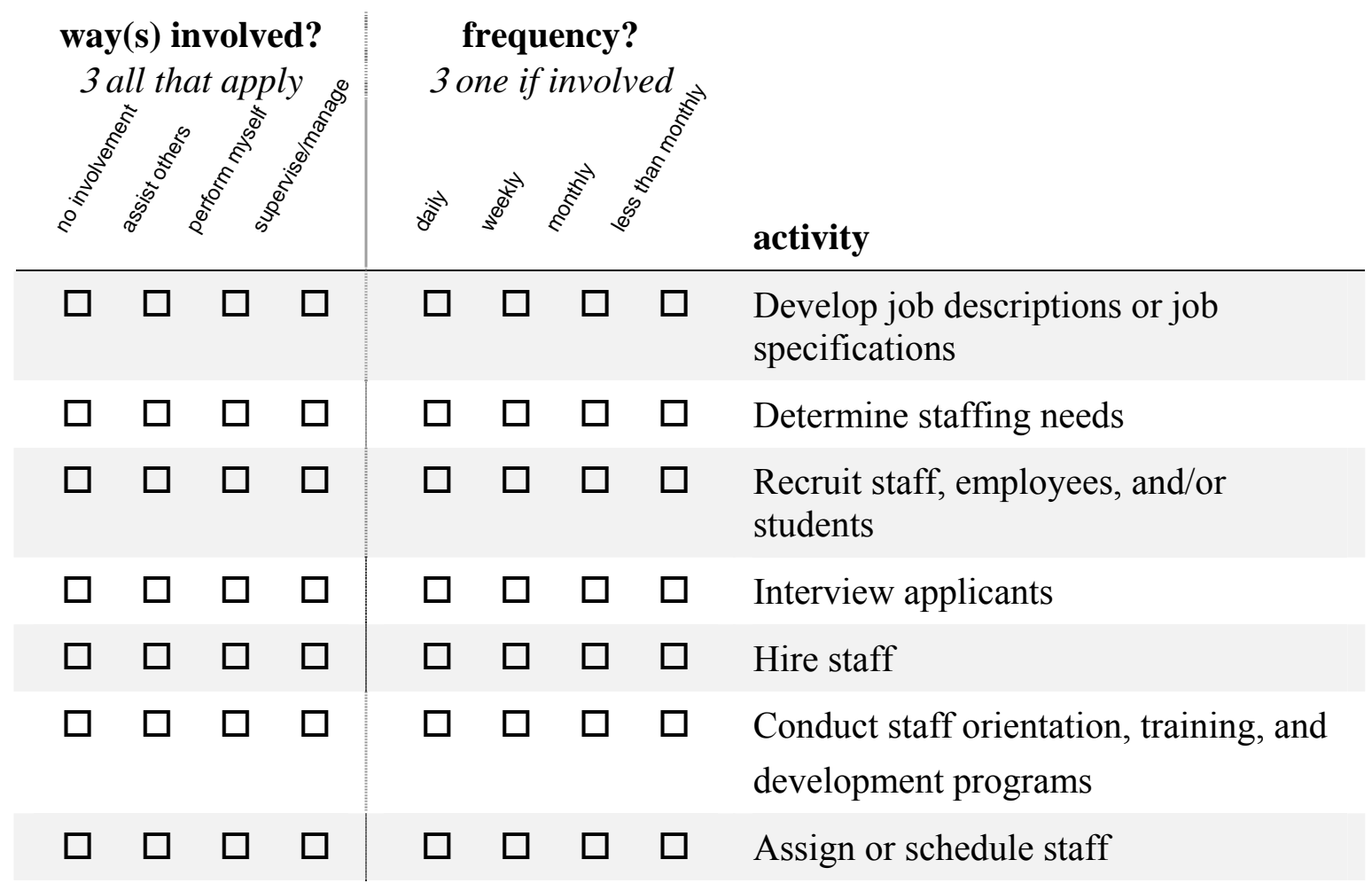




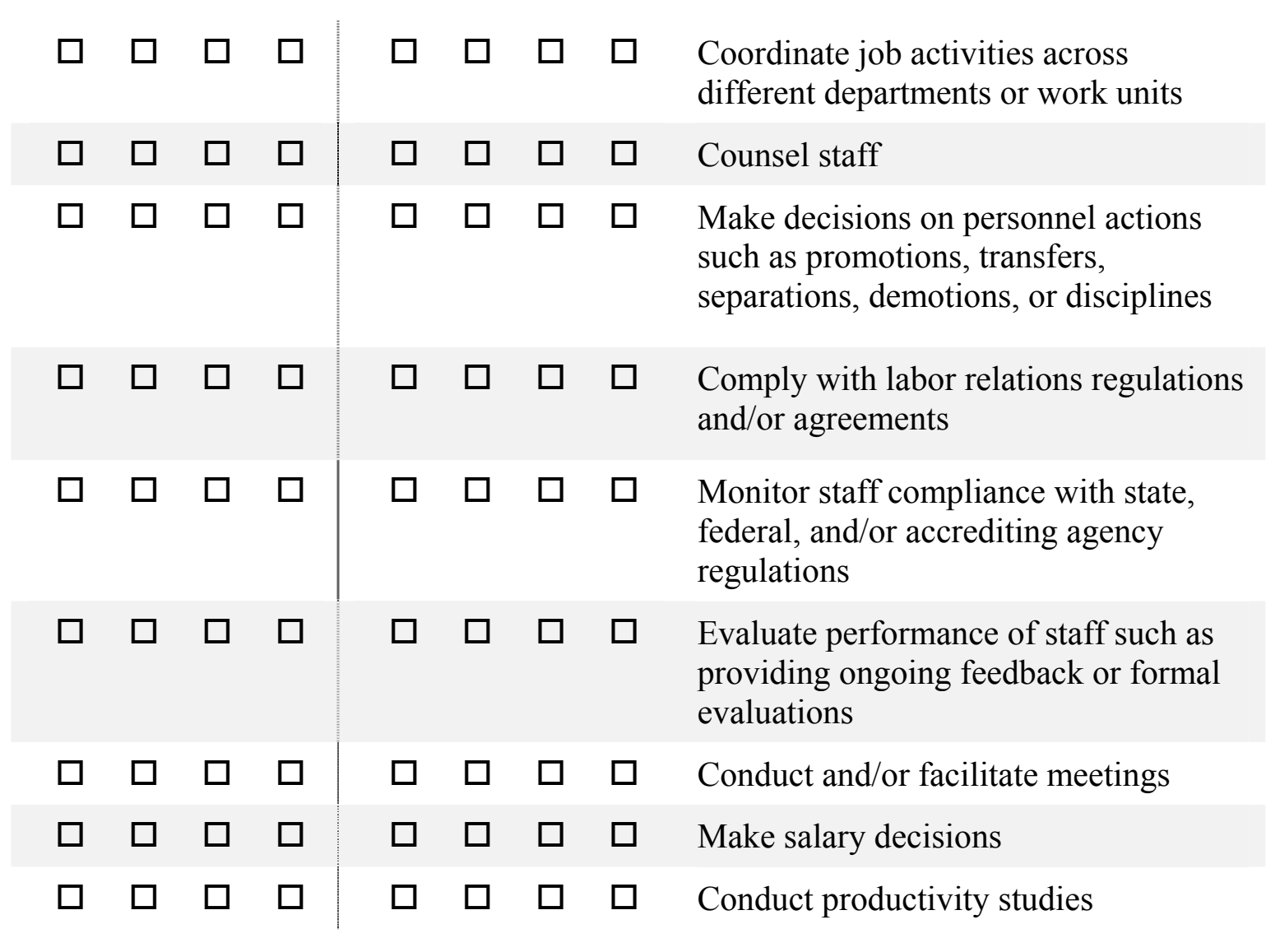

Please carefully read and respond to each activity — do not assume that whole sections do not apply to your position.

\section{Activities in your primary position: marketing of services and products}

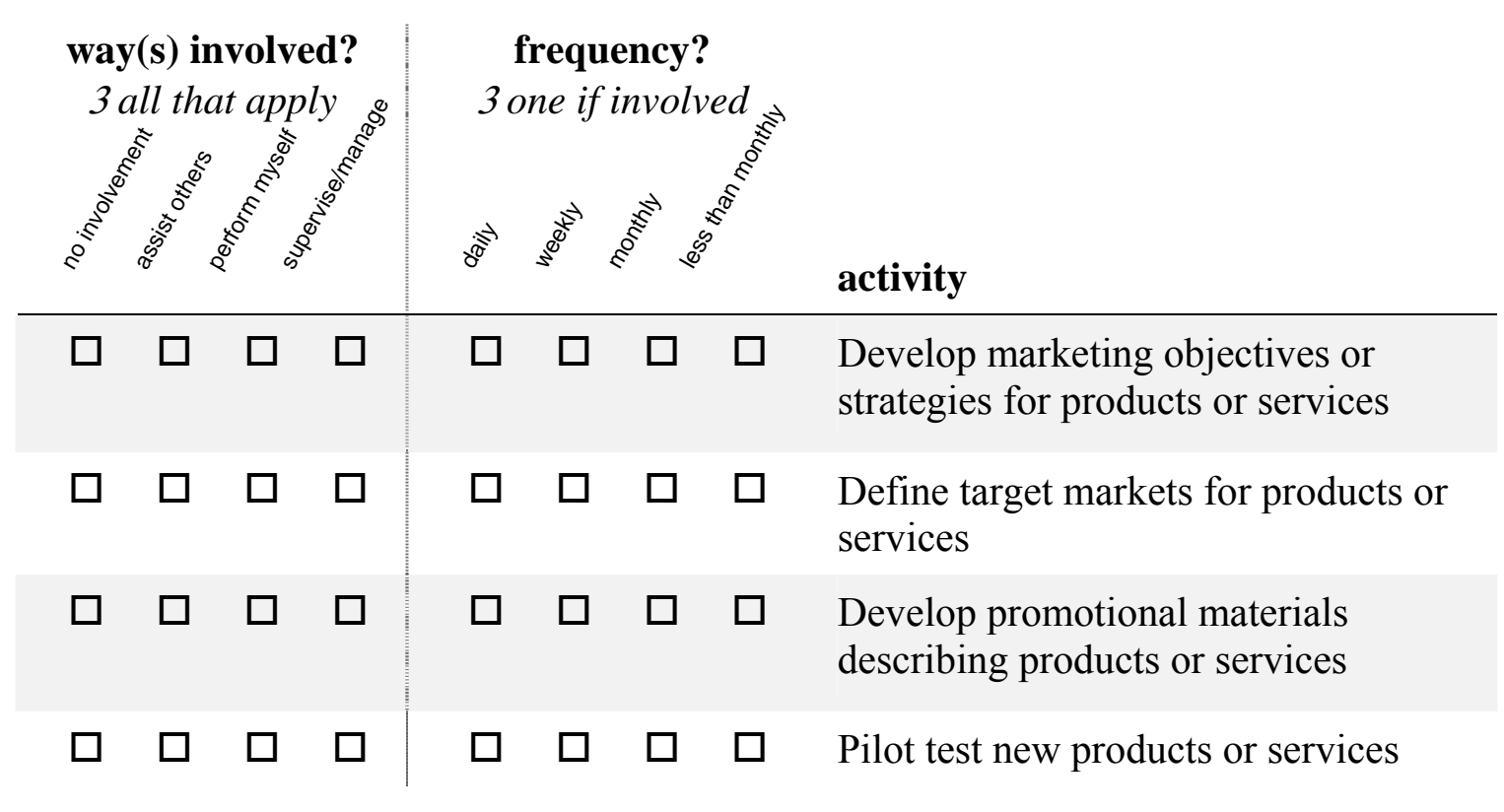



$\square \quad \square \quad \square \quad \square$
$\square \quad \square \quad \square \quad \square$
Implement marketing plan
$\begin{array}{llll}\square & \square & \square & \square \\ \square & \square & \square & \square \\ \square & \square & \square & \square\end{array}$
$\square \quad \square \quad \square \quad \square \quad$ Sell products or services
$\square \quad \square \quad \square \quad \square$
$\square \quad \square \quad \square \quad \square$
Evaluate marketing plan
Prepare cost comparison and analysis
for customers
Conduct an in-depth investigation and analysis of your competition to assess your place in the marketplace

\section{Activities in your primary position: conducting research}

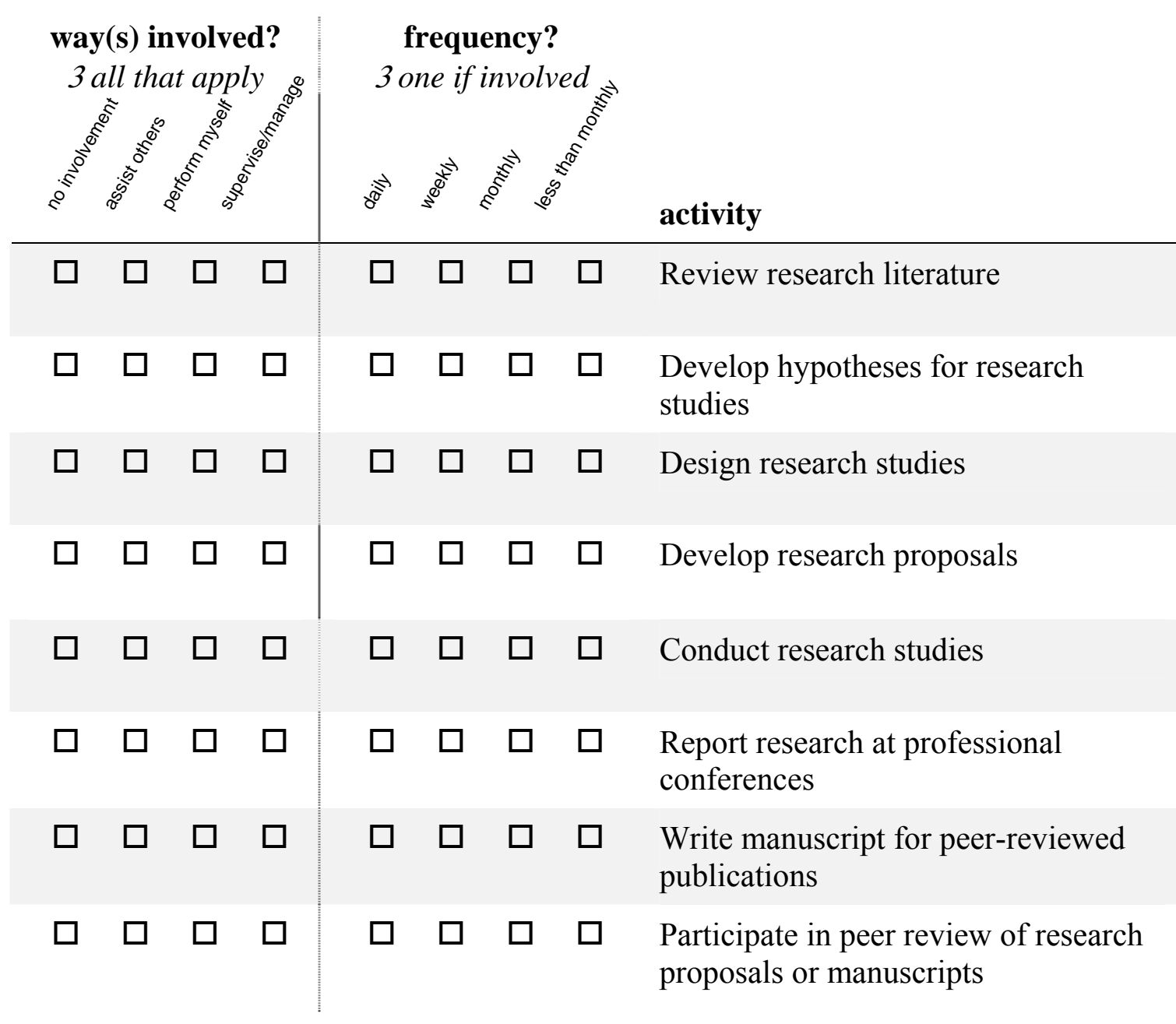


Please carefully read and respond to each activity — do not assume that whole sections do not apply to your position.

\section{Activities in your primary position: managing food and other material resources}

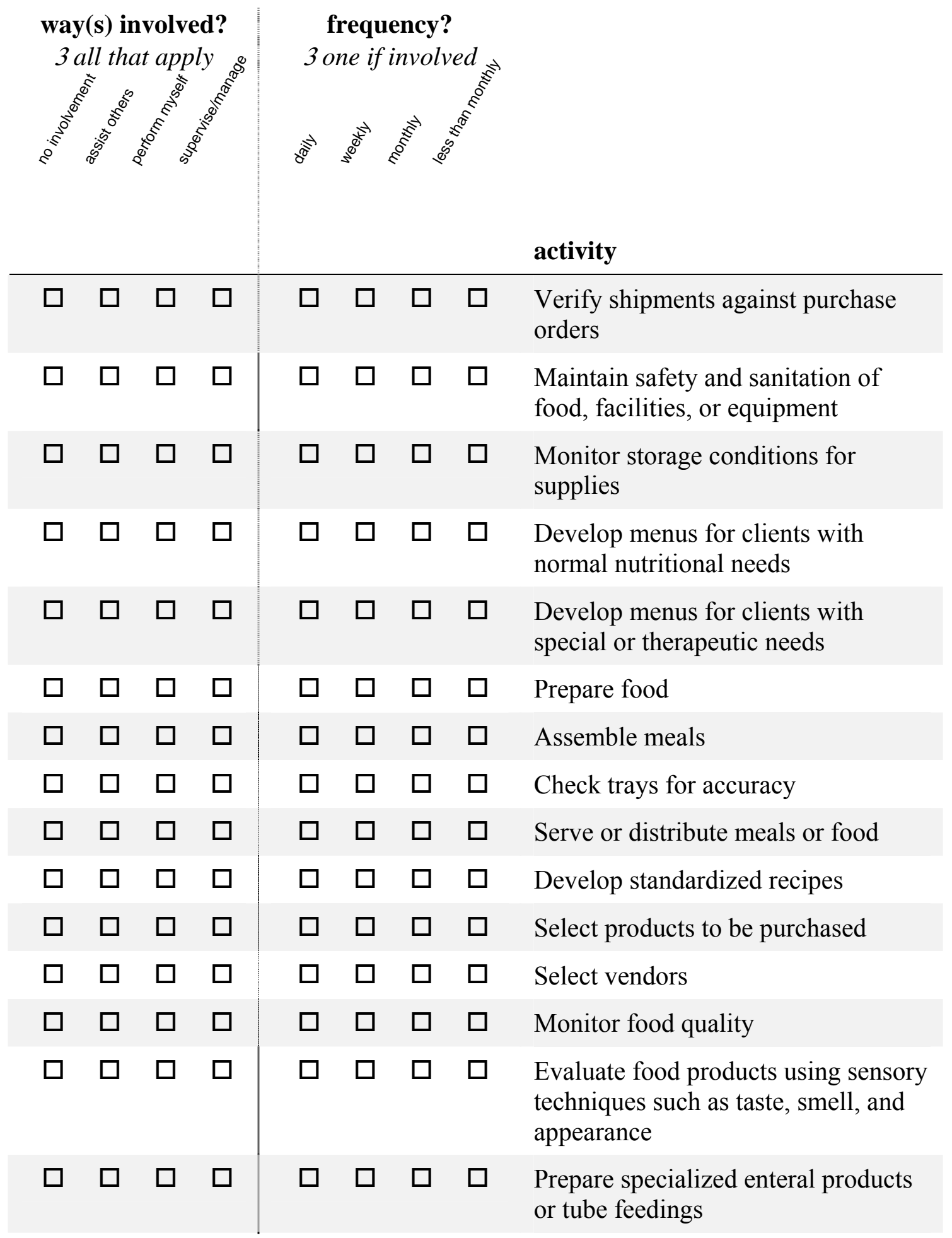




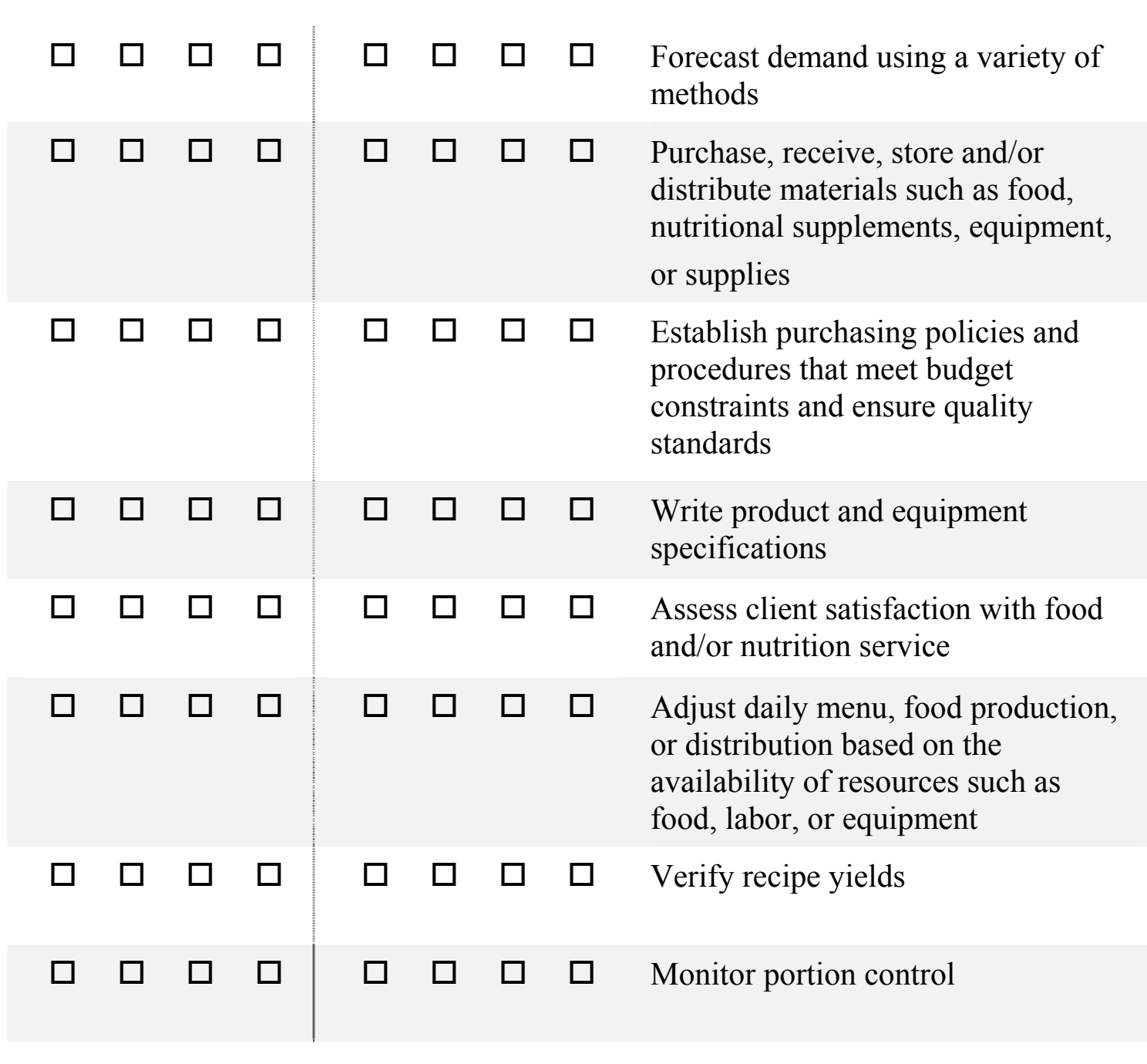

Please carefully read and respond to each activity — do not assume that whole sections do not apply to your position.

Activities in your primary position: managing financial resources

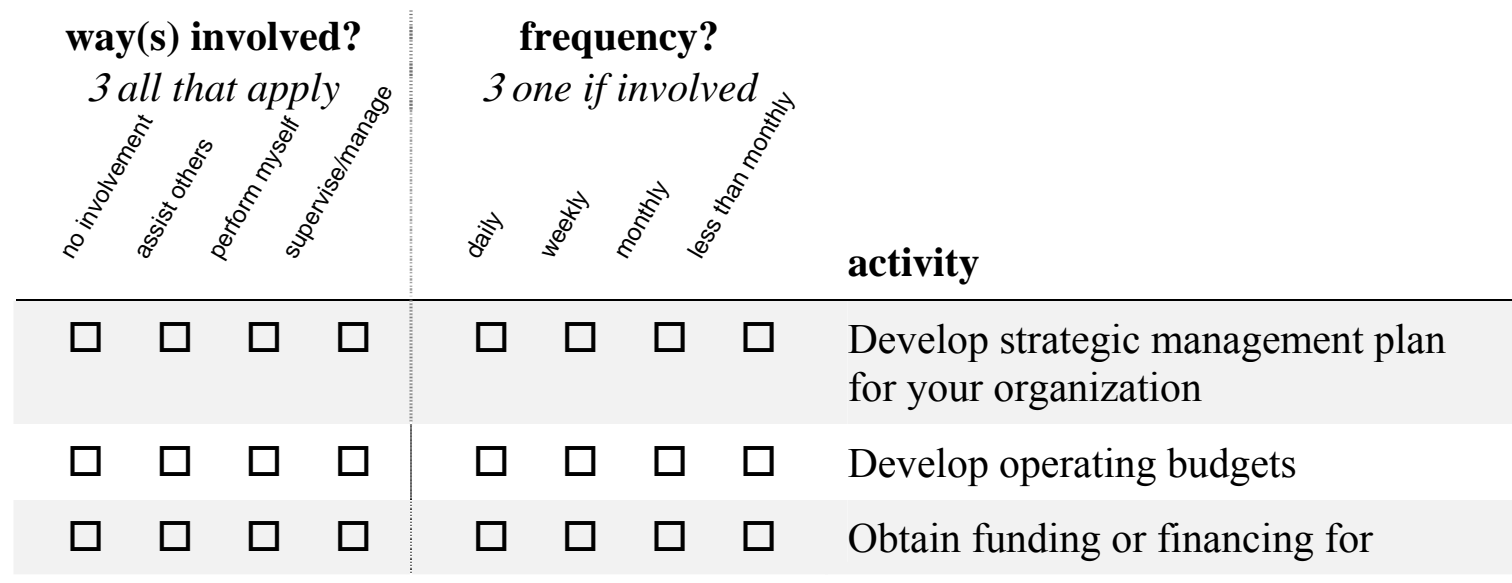




\begin{tabular}{|c|c|c|c|c|c|c|c|c|}
\hline & & & & & & & & projects \\
\hline$\square$ & $\square$ & $\square$ & $\square$ & $\square$ & $\square$ & $\square$ & $\square$ & Distribute resources based on a budget \\
\hline$\square$ & $\square$ & $\square$ & $\square$ & $\square$ & $\square$ & $\square$ & $\square$ & $\begin{array}{l}\text { Develop capital budget; e.g., major } \\
\text { expenses for large pieces of equipment }\end{array}$ \\
\hline$\square$ & $\square$ & $\square$ & $\square$ & $\square$ & $\square$ & $\square$ & $\square$ & Monitor financial performance \\
\hline$\square$ & $\square$ & $\square$ & $\square$ & $\square$ & $\square$ & $\square$ & $\square$ & $\begin{array}{l}\text { Establish procedures to protect against } \\
\text { financial loss }\end{array}$ \\
\hline$\square$ & $\square$ & $\square$ & $\square$ & $\square$ & $\square$ & $\square$ & $\square$ & $\begin{array}{l}\text { Develop methods for reducing or } \\
\text { maintaining costs }\end{array}$ \\
\hline$\square$ & $\square$ & $\square$ & $\square$ & $\square$ & $\square$ & $\square$ & $\square$ & $\begin{array}{l}\text { Implement methods for reducing or } \\
\text { maintaining costs }\end{array}$ \\
\hline$\square$ & $\square$ & $\square$ & $\square$ & $\square$ & $\square$ & $\square$ & $\square$ & $\begin{array}{l}\text { Establish prices for product, services, } \\
\text { or menu items }\end{array}$ \\
\hline$\square$ & $\square$ & $\square$ & $\square$ & $\square$ & $\square$ & $\square$ & $\square$ & Collect fees and/or reconcile accounts \\
\hline$\square$ & $\square$ & $\square$ & $\square$ & $\square$ & $\square$ & $\square$ & $\square$ & $\begin{array}{l}\text { Prepare financial analyses and/or } \\
\text { reports }\end{array}$ \\
\hline$\square$ & $\square$ & $\square$ & $\square$ & $\square$ & $\square$ & $\square$ & $\square$ & $\begin{array}{l}\text { Evaluate the financial performance of } \\
\text { products or services }\end{array}$ \\
\hline
\end{tabular}

\section{Activities in your primary position: managing facilities}

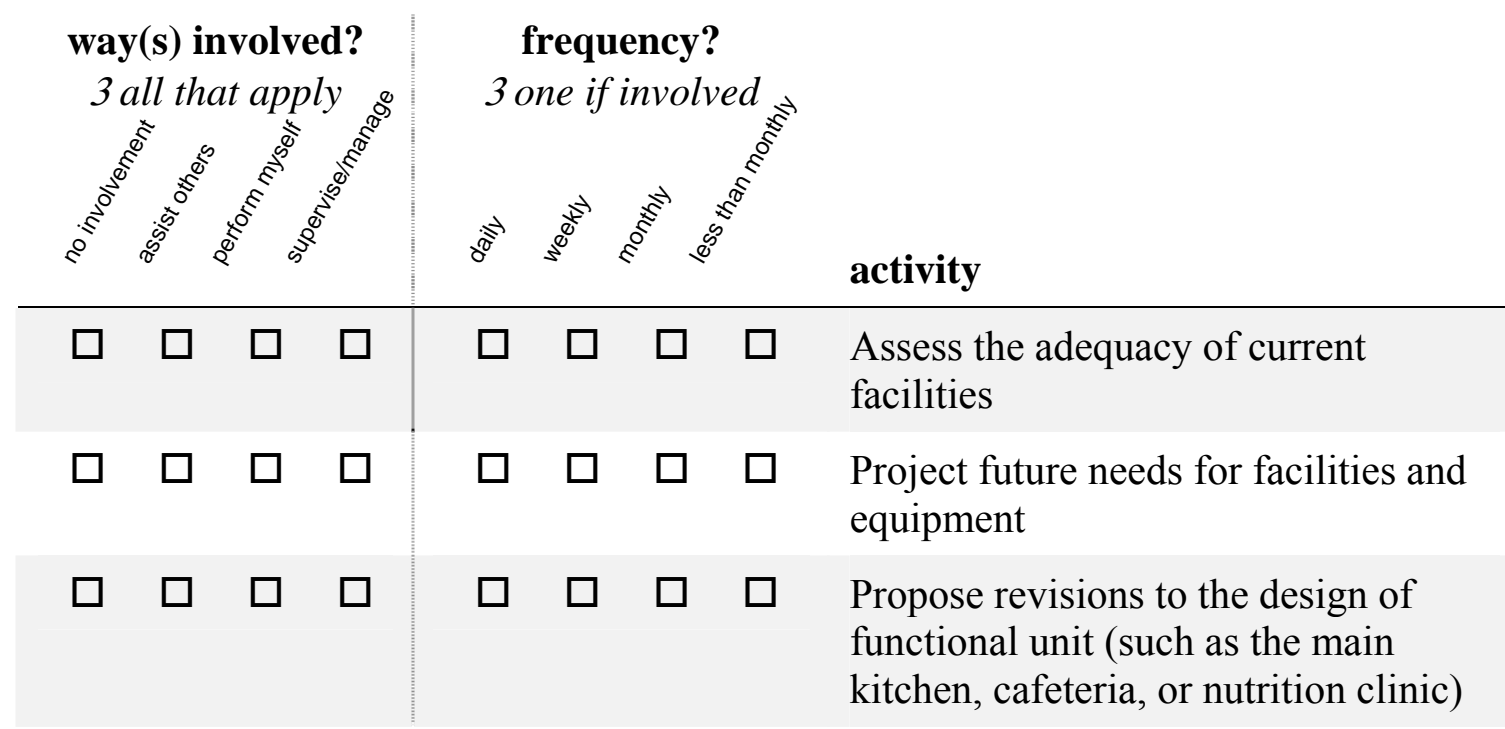




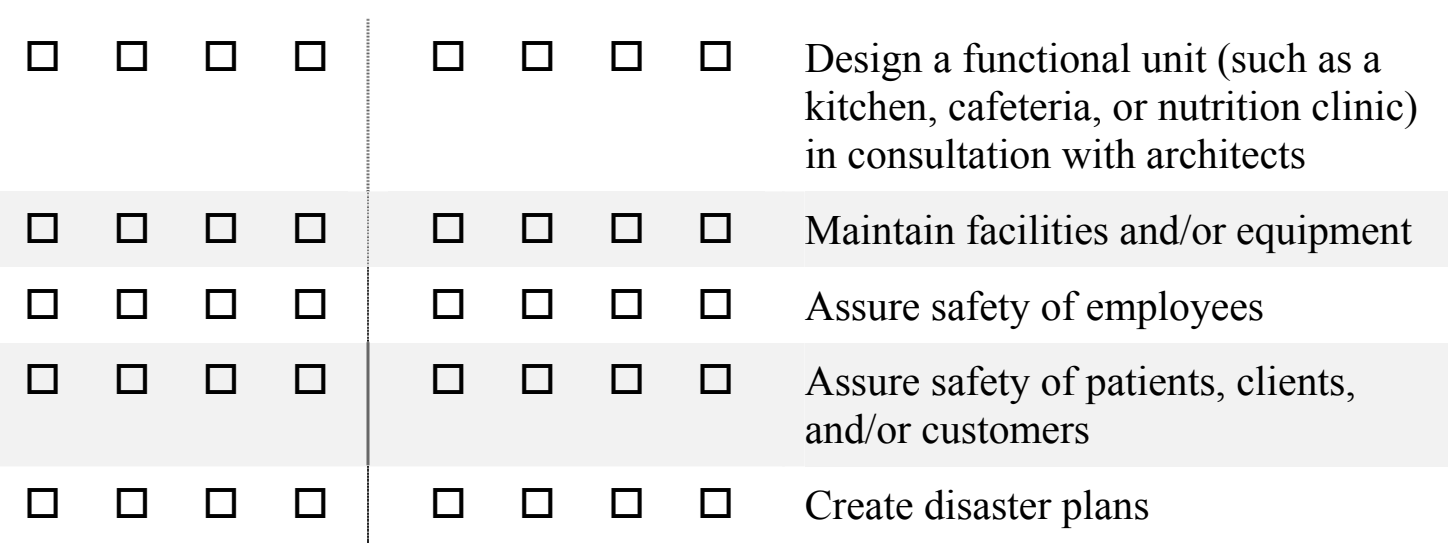

Please carefully read and respond to each activity — do not assume that whole sections do not apply to your position.

\section{Activities in your primary position: community/clinical general}
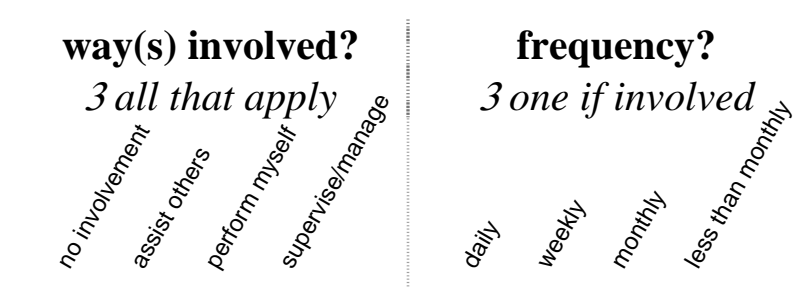

activity

\begin{tabular}{|c|c|c|c|c|c|c|c|c|}
\hline & & & & & & & & $\begin{array}{l}\text { For individuals or populations with } \\
\text { uncomplicated instances of common } \\
\text { conditions: }\end{array}$ \\
\hline$\square$ & $\square$ & $\square$ & $\square$ & $\square$ & $\square$ & $\square$ & $\square$ & Complete nutrition assessment \\
\hline$\square$ & $\square$ & $\square$ & $\square$ & $\square$ & $\square$ & $\square$ & $\square$ & $\begin{array}{l}\text { Determine nutrition diagnoses or } \\
\text { problems }\end{array}$ \\
\hline$\square$ & $\square$ & $\square$ & $\square$ & $\square$ & $\square$ & $\square$ & $\square$ & Establish nutrition care goals \\
\hline$\square$ & $\square$ & $\square$ & $\square$ & $\square$ & $\square$ & $\square$ & $\square$ & $\begin{array}{l}\text { Determine nutrient intervention to } \\
\text { address nutrition diagnosis or } \\
\text { problem }\end{array}$ \\
\hline$\square$ & $\square$ & $\square$ & $\square$ & $\square$ & $\square$ & $\square$ & $\square$ & $\begin{array}{l}\text { Evaluate nutrition outcomes } \\
\text { For individuals or populations with } \\
\text { complex medical conditions: }\end{array}$ \\
\hline$\square$ & $\square$ & $\square$ & $\square$ & $\square$ & $\square$ & $\square$ & $\square$ & Complete nutrition assessment \\
\hline$\square$ & $\square$ & $\square$ & $\square$ & $\square$ & $\square$ & $\square$ & $\square$ & $\begin{array}{l}\text { Determine nutrition diagnoses or } \\
\text { problems }\end{array}$ \\
\hline
\end{tabular}



\begin{tabular}{llll|lllll}
$\square$ & $\square$ & $\square$ & $\square$ & $\square$ & $\square$ & $\square$ & Establish nutrition care goals
\end{tabular}
Provide nutrition education programs to groups

Please carefully read and respond to each activity — do not assume that whole sections do not apply to your position.

Activities in your primary position: providing nutrition care to individuals

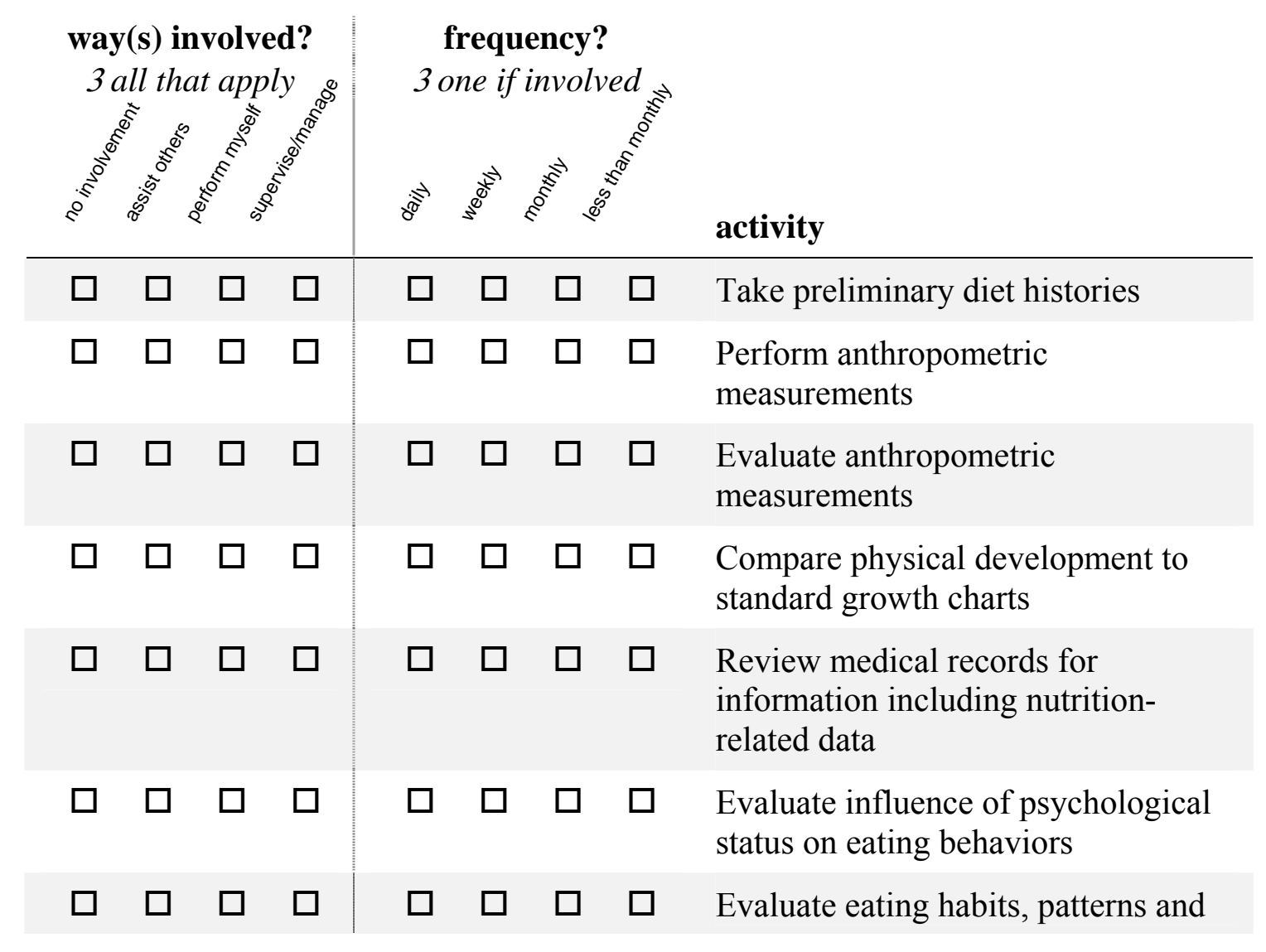




\begin{tabular}{|c|c|c|c|c|c|c|c|c|}
\hline & & & & & & & & choices of clients \\
\hline$\square$ & $\square$ & $\square$ & $\square$ & $\square$ & $\square$ & $\square$ & $\square$ & Compare lab results to normal values \\
\hline$\square$ & $\square$ & $\square$ & $\square$ & $\square$ & $\square$ & $\square$ & $\square$ & $\begin{array}{l}\text { Calculate nutrient requirements such } \\
\text { as the BEE }\end{array}$ \\
\hline$\square$ & $\square$ & $\square$ & $\square$ & $\square$ & $\square$ & $\square$ & $\square$ & Calculate fluid requirements \\
\hline$\square$ & $\square$ & $\square$ & $\square$ & $\square$ & $\square$ & $\square$ & $\square$ & Calculate electrolyte requirements \\
\hline$\square$ & $\square$ & $\square$ & $\square$ & $\square$ & $\square$ & $\square$ & $\square$ & $\begin{array}{l}\text { Calculate nutrition intakes, e.g., } \\
\text { calorie count }\end{array}$ \\
\hline$\square$ & $\square$ & $\square$ & $\square$ & $\square$ & $\square$ & $\square$ & $\square$ & Evaluate intake of specific nutrients \\
\hline$\square$ & $\square$ & $\square$ & $\square$ & $\square$ & $\square$ & $\square$ & $\square$ & Recommend nutrition status lab tests \\
\hline$\square$ & $\square$ & $\square$ & $\square$ & $\square$ & $\square$ & $\square$ & $\square$ & $\begin{array}{l}\text { Write orders for nutrition status lab } \\
\text { tests }\end{array}$ \\
\hline$\square$ & $\square$ & $\square$ & $\square$ & $\square$ & $\square$ & $\square$ & $\square$ & Evaluate and monitor medications \\
\hline$\square$ & $\square$ & $\square$ & $\square$ & $\square$ & $\square$ & $\square$ & $\square$ & $\begin{array}{l}\text { Help patients/residents with daily } \\
\text { menu selection }\end{array}$ \\
\hline$\square$ & $\square$ & $\square$ & $\square$ & $\square$ & $\square$ & $\square$ & $\square$ & $\begin{array}{l}\text { Adapt regular oral diets to meet } \\
\text { individual preferences or needs }\end{array}$ \\
\hline$\square$ & $\square$ & $\square$ & $\square$ & $\square$ & $\square$ & $\square$ & $\square$ & $\begin{array}{l}\text { Plan oral diets with multiple } \\
\text { nutritional requirements }\end{array}$ \\
\hline$\square$ & $\square$ & $\square$ & $\square$ & $\square$ & $\square$ & $\square$ & $\square$ & Recommend diets \\
\hline$\square$ & $\square$ & $\square$ & $\square$ & $\square$ & $\square$ & $\square$ & $\square$ & $\begin{array}{l}\text { Recommend nutritional supplements } \\
\text { for clients on oral diets }\end{array}$ \\
\hline$\square$ & $\square$ & $\square$ & $\square$ & $\square$ & $\square$ & $\square$ & $\square$ & Write orders for clients on oral diets \\
\hline$\square$ & $\square$ & $\square$ & $\square$ & $\square$ & $\square$ & $\square$ & $\square$ & $\begin{array}{l}\text { Provide advice on safe, effective use } \\
\text { of herbals, botanicals, and other } \\
\text { dietary supplements }\end{array}$ \\
\hline$\square$ & $\square$ & $\square$ & $\square$ & $\square$ & $\square$ & $\square$ & $\square$ & Recommend tube feeding therapies \\
\hline$\square$ & $\square$ & $\square$ & $\square$ & $\square$ & $\square$ & $\square$ & $\square$ & $\begin{array}{l}\text { Write orders for tube feeding } \\
\text { therapies }\end{array}$ \\
\hline$\square$ & $\square$ & $\square$ & $\square$ & $\square$ & $\square$ & $\square$ & $\square$ & $\begin{array}{l}\text { Recommend intravenous or } \\
\text { parenteral nutrition therapies }\end{array}$ \\
\hline
\end{tabular}




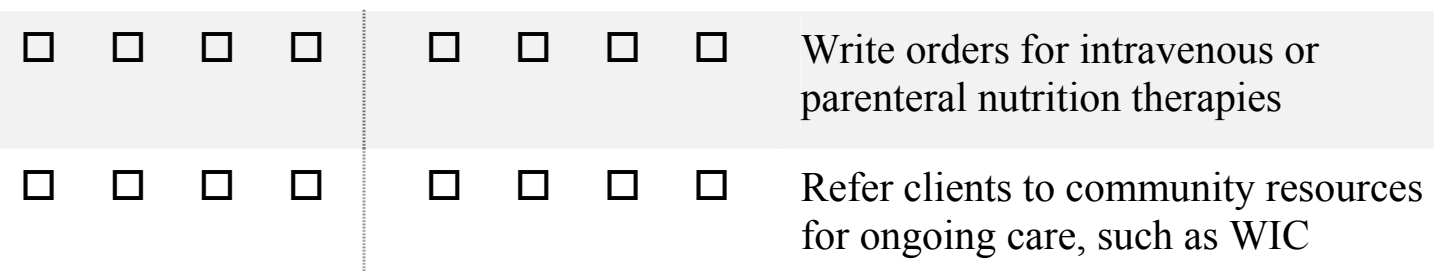

Please carefully read and respond to each activity — do not assume that whole sections do not apply to your position.

\section{Activities in your primary position: providing nutrition care to individuals} (continued)

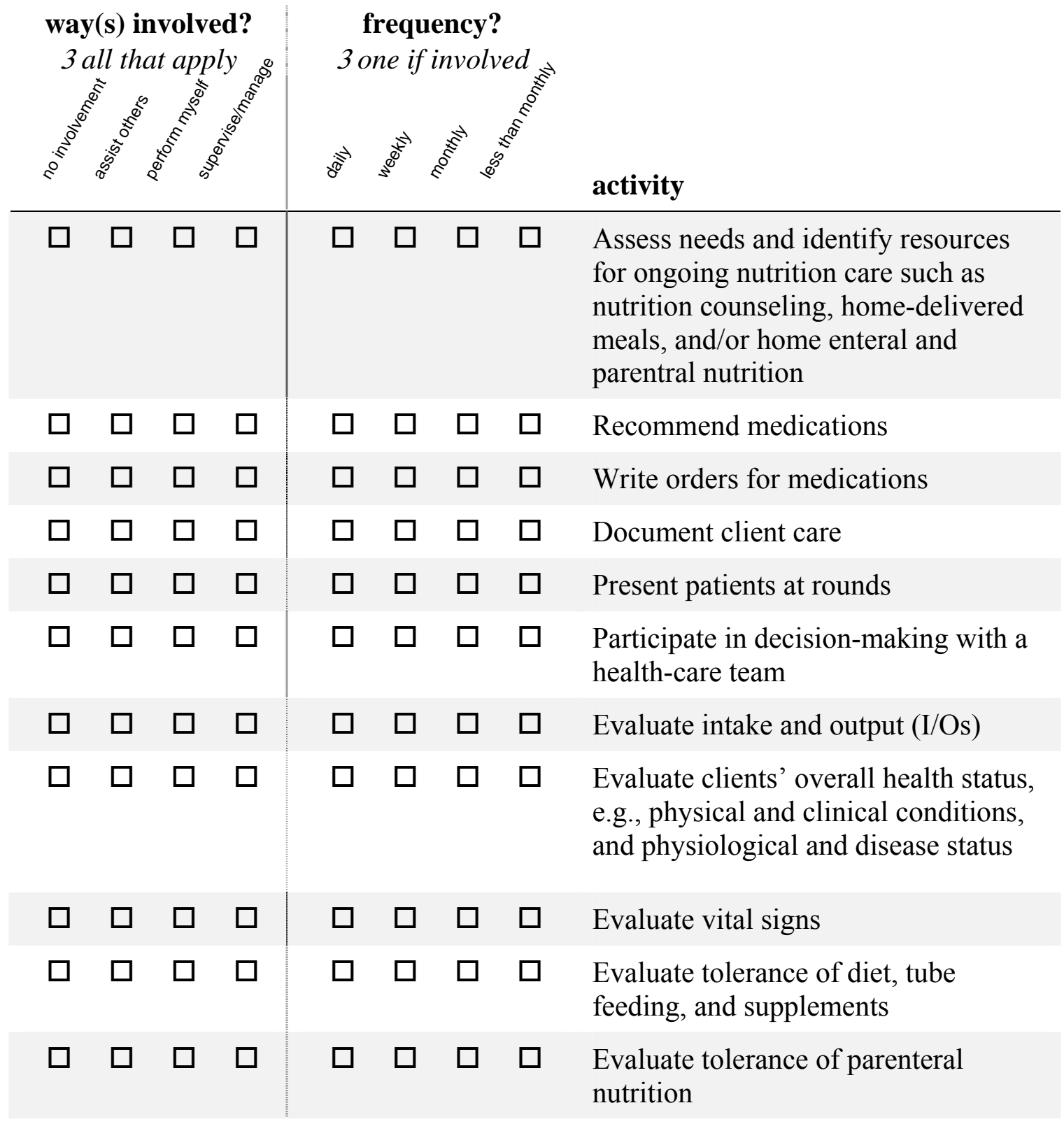



$\begin{array}{llll}\square & \square & \square & \square \\ \square & \square & \square & \square\end{array} \mid$
$\begin{array}{llll}\square & \square & \square & \square \\ \square & \square & \square & \square\end{array}$
Act as case manager
Develop institutional standards of nutrition care

Please carefully read and respond to each activity — do not assume that whole sections do not apply to your position.

Activities in your primary position: providing nutrition programs for population groups

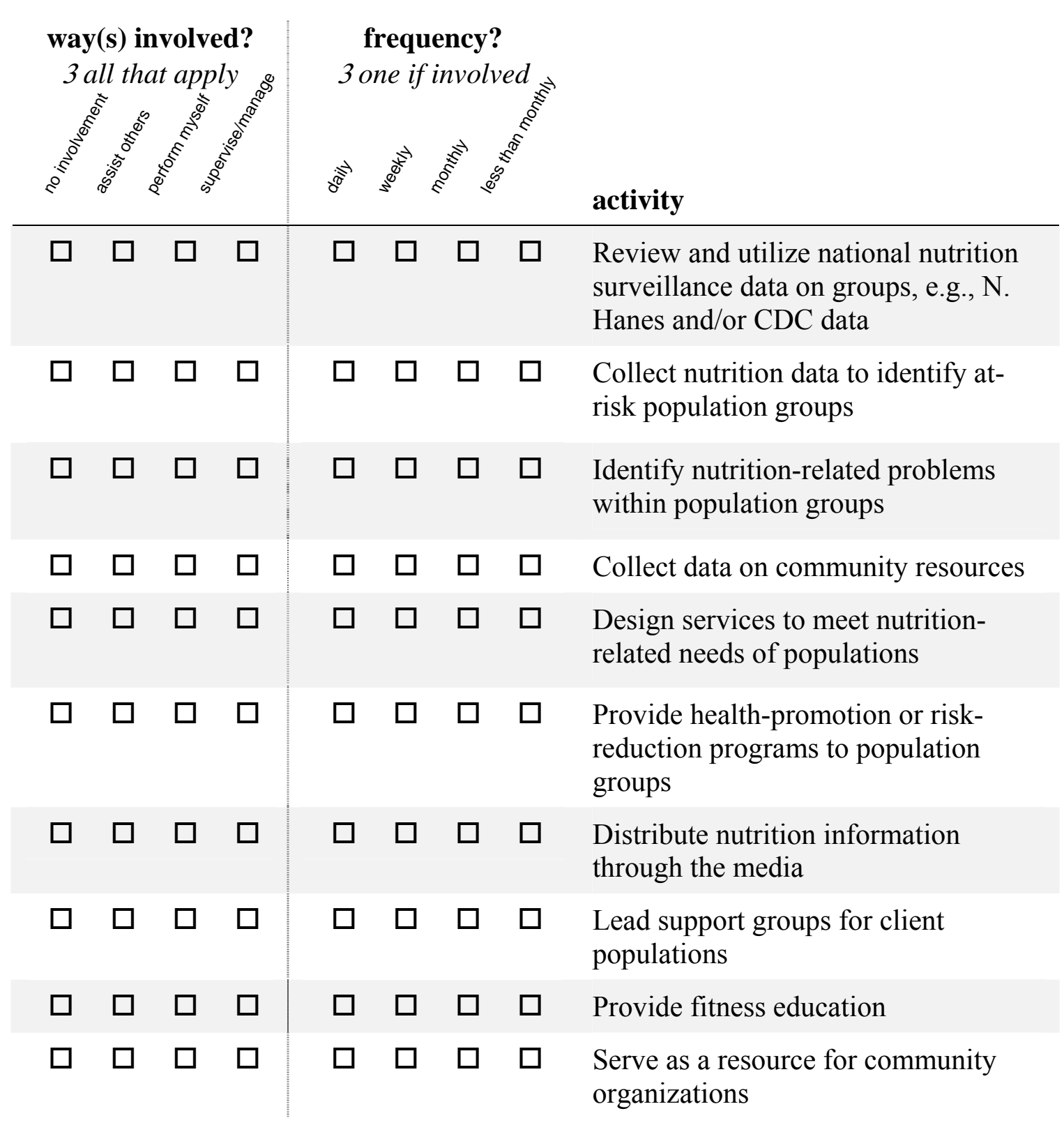



$\begin{array}{llll}\square & \square & \square & \square\end{array}$
$\square \quad \square \quad \square \quad \square$
Develop programs that increase
availability of food to target groups

22. Are there other activities (not listed above) that are an important part of your responsibilities in your primary position?

$\square$ no

$\square$ yes ... please specify:

23. Are there any activities with which you are involved at least monthly for which you feel you were not adequately prepared by your dietetics education and internship?

$\square$ no

$\square$ yes ... please specify: 
24a. What subject areas included in your dietetics educational preparation are most applicable to your dietetics practice?

24b. What subject areas included in your dietetics educational preparation are least applicable to your dietetics practice?

\section{Any additional comments?}

\section{THANK YOU!}

(Please check that you've answered all questions on all 16 pages, then return your survey using the stamped reply envelope provided.)

This form is coded only to avoid troubling you with reminder mailings once your survey is received.

Your answers will be kept completely confidential and used only in tabulation with others. (C) 2005

V1-RD project \# 11051 -

$\bigotimes$ Readex 